\title{
Valences and sense of personal autonomy with regard to professional development in Dutch primary teachers: Do decision contexts and age make a difference?
}

\author{
Folke J. Glastra ${ }^{1}$ \& Cornelis J. de Brabander ${ }^{1,2}$ \\ ${ }^{1}$ Department of Educational Studies, Leiden University, The Netherlands \\ ${ }^{2}$ Query Informatisering, Voorhout, The Netherlands
}

Article received 5 April 2021 / Article revised 9 August / Accepted 9 September / Available online 15 October

\begin{abstract}
In this study on motivations concerning professional development (PD) we interviewed 95 primary school teachers in the Netherlands. We coded these data using the Unified Model of Task-specific Motivation (de Brabander \& Martens, 2014) in different decision contexts concerning who decides about teacher participation in PD: school board, teacher teams, or individual teachers. We analysed the valences that teachers associated with PD activities, their experiences of autonomy, and whether and how these variables were affected by decision context and teacher age. Results show that decision contexts relate differently to valences and autonomy experiences. Positive autonomy and positive valences increased going from school board to team to individual decision contexts. Whereas the literature on effective teacher PD stresses the importance of PD design features, our study is the first to empirically demonstrate the crucial influence of decision contexts. Among older teachers, teaching experience informed the selection of PD content to transfer to their classrooms. Younger teachers tended to first explore whether $P D$ worked in their classrooms before deciding about adoption. Direct applicability emerged as a dominant criterion for evaluating $P D$. Decision context and autonomy regarding $P D$ programmes play important roles in ensuring applicability. Our research revealed that the dominance of the direct applicability criterion was not motivated by student benefits alone. It was also based on an attitude of efficiency among primary teachers, reflecting growing work pressures and a general prioritisation of classroom teaching above all other tasks, including $P D$.
\end{abstract}

Keywords: Task-specific motivation; professional development; primary teachers; decision contexts; teaching experience 


\section{Introduction}

Stimulated by the transformation of advanced nations into knowledge societies that compete with each other on the strength of their knowledge base, and by international rankings of student performance (PISA, TIMSS, PIRLS), national educational systems around the world have been faced with demands for higher student performance outcomes (Borko, 2004). At the same time, the alleged insufficient quality of teachers and teacher education has been highlighted in national debates (Ministerie van OCW, 2012; Webb et al, 2004). In many places, these demands for higher standards and performance-based approaches of learning have coincided with the devolvement of educational responsibilities from the central government to the level of the school (board) (Ball, 2003). This has prompted the strengthening of external assessments by educational inspectorates, as witnessed in the case of the UK by OfSTED (Hall \& Noyes, 2009), and the establishment of a system of internal quality controls for accountability purposes within schools (Karsten, 1999). These educational reform programmes, together with developments such as the growing digitalisation, ultimately rely for their realisation on teachers and their teaching practices (Borko, 2004). Teachers are required to develop new skills, knowledge, and attitudes; in short, "new professionalism" (Webb et al., 2004; Day et al., 2005). However, research has revealed resistance from teachers to the implications of these reform programmes for their professional autonomy (Leithwood et al., 2002; Locke et al., 2005; Moore et al., 2002). To address demands for reform and to overcome resistance, teacher education had to be improved. Moreover, the continuing professional development (PD) of teachers was given a pivotal role in raising standards and attaining educational reform goals (Hochberg \& Desimone, 2010). This had to be PD that is effective. In policy discourse, the hallmark of effective PD is teacher quality enhancement leading to gains in student performance (cf. Little \& Bartlett, 2010). However, experts are not in agreement about what exactly constitutes effective teacher PD (cf. Wilson \& Berne, 1999).

\subsection{Effective teacher professional development: a short review}

There is extensive literature on effective teacher PD (Borko, 2004; Clark et al., 2012; DarlingHammond \& Richardson, 2009; Desimone, 2009; Garet et al., 2001; Penuel et al., 2007). Desimone (2009) defines effective PD as learning activities resulting in increased teacher knowledge and skills, improvements in practice, and increases in student achievement. It focuses on content knowledge, makes use of active learning arrangements, is coherent with teacher beliefs and knowledge as well as the external reform and policy context, is not a one-off but has a longer duration and is characterised by collective participation that fosters collaboration. Penuel et al. (2007) identify similar aspects of effective PD. They differ from Desimone, however, in that they find teaching strategies just as valuable in PD as content knowledge. Darling-Hammond and Richardson (2009) state that effective teacher PD should be part of a school reform effort, which requires collective participation and collaboration to be successful.

The above conceptions of effective teacher PD stress the role of design features in determining PD effectiveness. Van Duzor (2010) concentrates on the actual transfer of PD lessons to classroom practice and points out that teachers will be motivated for transfer when PD is coherent with their own teaching philosophies and fits both their own learning needs and those of their students. This should be achieved by actively integrating teachers' professional expertise into their PD. PD should constitute teacher learning, rather than teacher training from a deficit perspective.

Schibeci and Hickey (2004) take this argument a step further. Like Van Duzor, they suggest that PD will only pay off if it fits teacher needs and classroom contexts. However, they argue that this cannot be achieved in mandatory PD. Only when teachers themselves decide on the content and process of PD will there be teacher learning, contextual relevance, and teacher-driven innovation (Emo, 2015). This point of view is also manifest in the "teacher communities of practice" literature (Vescio et al., 2008). Teachers are motivated when they are responsible for the organisation of their own PD (Hawley \& Valli, 
1999; Little, 2006). Kennedy (2016) concludes that teacher autonomy in PD stimulates the implementation of PD lessons, through increased motivation.

\subsection{Some corollaries for this investigation}

Besides identifying characteristics of effective PD according to the literature, this short overview of effective teacher PD leads to four observations. First, the allocation of responsibility for choice and organisation of teacher PD emerges as an important factor explaining teacher motivations for engaging in and implementing PD. The issue of the power relations that govern PD participation has rarely been investigated empirically. Therefore, the impact of who decides about PD - the school board, the team, or the individual teacher - on motivations, and teacher autonomy vis-à vis PD programmes, will be analysed in this study.

Second, most authors in our review seem to agree that PD can only be effective if it aligns with the beliefs and learning needs of teachers. From this point of view, it is remarkable that the literature pays little attention to the issue of teacher career and life cycles (Day \& Gu, 2007; Fox et al., 2015; Huberman, 1989; Maskit, 2011; Richter et al., 2011). As working conditions change and teaching experience accrues, learning needs may change. Therefore, we will investigate the role that teaching experience plays in motivations for PD.

Third, the literature focuses on what PD could and should be and much less on what it is. Little (1993) has pointed out that teacher PD appears as a patchwork of learning activities, predominantly involving teacher training in the form of short-term, packaged programmes, amounting to a fragmented curriculum (cf. Ball \& Cohen, 1999). This image of PD provision seems valid for the Dutch situation too, that constitutes the context of our study (SEOR, 2012; Van Veen et al., 2010). In this study, we approach this PD patchwork from the perspective of primary teachers. We define teacher PD broadly, as any activity that teachers engage in, individually or collectively, that is directed at or results in the development of their skills, knowledge, attitudes or practices (cf. Evans, 2014). Such activities may be formal, non-formal or informal; on-the-job or off-the-job; one-off or long-lasting; provided or selforganised.

Fourth, the literature on effective teacher PD, even where it argues for the necessity of teacher control, fails to acknowledge that such effectiveness is always to some degree contingent on the restrictions imposed by working relationships in primary education, the relative dominance of PD practices (Little, 1993), and teachers' professional beliefs. The insecurity that teachers experience regarding their contribution to the development of their students, as highlighted in the classic study of the schoolteacher by Lortie (1975), may serve as an illustration. Such insecurity results in a tendency to look for signs of teaching effect in the present and to seek short-term psychic rewards. It may predispose teachers to prefer interaction with their students over PD. Taking such PD motivations as the unquestioned basis for improving PD entails the risk of undermining conditions for both deep, innovative, and ground-breaking learning in PD and for school development. Therefore, we propose in this investigation to reflect on the motivational data gathered from the perspective of general attitudes to teaching and PD among teachers, as they are impacted by both the constraints and the potential of their schools as work environments.

The above debate constitutes the background for our investigation of (the impact of decision context and teaching experience on) motivation for PD among primary teachers. In this paper, our primary goal is to explore motivational aspects of PD to better understand the perspectives of primary teachers regarding PD. In the following section, we explain the motivation model guiding our research.

\subsection{Valences and autonomy in the Unified Model of Task-specific Motivation}

Our research into teachers' motivation for PD was guided by the Unified Model of Task-specific Motivation (UMTM; de Brabander \& Martens, 2014). For a full explanation of the UMTM, we refer to 
the theoretical proposal by De Brabander and Martens (2014) and empirical explorations of the model by De Brabander and Martens (2018) and De Brabander and Glastra (2018, 2021). In this section, we will introduce the concepts of valences and autonomy that form the focus of the current study.

The UMTM (de Brabander \& Martens, 2014) was intended as an integration of the task-specific aspects of different and partly conflicting theories of motivation, such as the self-determination theory (Ryan \& Deci, 2000, 2020), the (situative) expectancy-value theory of achievement motivation (Wigfield \& Eccles, 2000; Eccles \& Wigfield, 2020), the social-cognitive theory (Bandura, 1997; Schunk \& DiBenedetto, 2020), the person-object theory of interest (Krapp, 2005), and the theory of planned behaviour (Ajzen \& Fishbein, 2008). Furthermore, the UMTM also incorporates the approachavoidance distinction (Elliot, 2006). The UMTM aims to cover all the constructs needed to understand the motivation of a person for an activity in a specific situation at a certain point in time. More stable factors relating to the person or the context also influence motivation, but it is assumed that these factors find expression in task-specific constructs.

The definitions of the concepts used in this study are taken from De Brabander and Martens (2014), using adaptations by De Brabander and Glastra (2018, 2021). In the UMTM, motivation is defined as readiness for action. Readiness for action is influenced by a valence appraisal, to which both affective and cognitive valences contribute. Valence appraisal represents the overall attractiveness of an activity. Affective and cognitive valences are produced by separate and relatively independent systems of behaviour regulation.

Affective valences are defined as feelings that originate from undertaking an activity. Affective valences represent the levels of positive and negative feelings experienced when doing an activity. Any action that comes to mind as an action option immediately and unavoidably evokes the corresponding feelings. The reason for or function of such feelings is not necessarily known and is often unknown.

Cognitive valences are defined as the articulation and valuation of the consequences of performing an activity. Cognitive valences are brought about by active reflection of the actor. An activity has multiple consequences, intended and unintended, each of which will have a separate cognitive valence. The quality of cognitive valences obviously depends on the actor's competence to articulate and value the consequences of an activity.

Cognitive valences can be broken down into different parts depending on who receives the outcome value. Evidently, the first to profit from an activity is almost always the actor themselves. In the context of teacher PD, this would be the teacher, while students and the school are natural candidates for sources of non-personal cognitive valences. Affective valences have no non-personal component. Only the feelings the person experiences about an activity are relevant.

Affective valences and cognitive valences are defined as two theoretically independent categories of motives. What is pleasurable to do is generally also recognised as profitable and vice versa, but discrepancies between the two are also possible ("I know it is good for me, but I don't like it"). Affective and cognitive valences are combined on a common scale (valence appraisal) through interaction between different systems of behaviour regulation. In this respect, the UMTM adopts the position of the person-object theory of interest (Krapp, 2005) and differs from both self-determination theory and expectancy-value theories. In self-determination theory (Ryan \& Deci, 2020) intrinsic motivation (affective component) is opposed to extrinsic motivation (cognitive component), as extrinsic motivation diminishes intrinsic motivation. Expectancy-value theories, on the other hand, define affective and cognitive aspects as facets of the same value construct, summing to a total value.

The distinction between affective and cognitive valences is combined with the distinction between approach and avoidance motivation (Elliot, 2006). This distinction is related to the possibility of valences being positive or negative. Positive valences call for an action that promises to realise them. Negative valences prompt refraining from an action or initialising a counter-action in order to prevent their realisation. Approach and avoidance motivation are also seen as being regulated by different systems (Carver, 2006). Combining the distinction between positive and negative valences with the 
distinction between affective and cognitive valences gives rise to four relatively independent motivational components. Together, these combine to form a resultant value, which is called valence appraisal, which in turn determines readiness for action.

Valences are influenced in the first place by their task-specific precursors. The UMTM encompasses the concepts of autonomy, feasibility, relatedness, and subjective norm. In this study, we will make use of the concept of autonomy. Autonomy refers to the origin of the action: this may be the self, or an internal or external source that is experienced as foreign. In UMTM, a higher level of taskspecific autonomy can lead to increased task-specific motivation, because it can affect the level of affective and cognitive valences.

The model makes a distinction between individuals and their contexts, which leads to a partition of some components in the model, among them autonomy. The personal facet of autonomy is labelled "sense of personal autonomy", and is defined as the extent to which a person experiences themselves as the originating force that drives the performance of an activity. The distinction here concerns whether the self feels that it is driving or being driven. The contextual part of autonomy is labelled "perceived freedom of action", and entails the liberty a person perceives in the action context to decide independently about the choice and execution of action alternatives (cf. Reeve et al., 2003). Of course, the two aspects are related; their fundamental distinctiveness, however, is revealed by the possibility that one can still experience the self as the driving force in a situation where one has no freedom of action.

While autonomy is identified as a general human need in motivation theory (Ryan \& Deci, 2000), it has specific significance in the work of teachers. This relates to the status of teachers as professional employees, who exercise a high level of discretion in the relative isolation of their classrooms. Research shows an association between teacher autonomy and engagement, job satisfaction, and emotional exhaustion (Pearson \& Moomaw, 2006; Skaalvik \& Skaalvik, 2014). However, in times of standardisation of national curricula, standardised testing, and doubts about the competence of primary teachers, teacher autonomy as a strong motivational component within the teaching profession is called into question (Apple \& Jungck, 1990; Ball, 2003; Ballet \& Kelchtermans, 2009; Clark, et al., 2012; Gleeson \& Husbands, 2003; Hardy \& Lingard, 2008; Milner, 2013; Stevenson et al., 2007). Therefore, in our investigation, we pay particular attention to the role of autonomy in PD motivation.

\subsection{Research concerning decision contexts and participation in PD}

The debate concerning teacher autonomy manifests itself in PD issues too: should participation be determined by teachers themselves, or by governmental educational reform agendas (Borko et al., 2002; Starkey et al., 2009). In 2012, the Dutch Ministry of Education (2012, pp. 18-20) saw its educational reform agenda increasingly reflected in school board and teachers' PD choices. A survey among Dutch primary and secondary teachers (Onderwijscoöperatie, 2016) reported that decisions about teacher participation in PD were made by school boards in $48 \%$ of cases, by teachers in $1 \%$ of cases, and by both parties jointly in 36\% of cases. According to Clark et al. (2012), teachers in Canada experienced increasing constraints in determining PD participation. Policy-driven, compulsory, and often one-size-fits-all PD programmes met with fierce criticism from these teachers (Locke et al., 2005).

The current study examines three decision contexts: decisions concerning participation in PD made by the school board, by the team, or by individual teachers. In most cases, school board PD decisions are made for groups or whole teams of teachers, and they are binding. They may be the outcome of local school board decisions, but often they result from government educational policies or inspectorate reports (SEOR, 2012). Team decisions are based on collectively defined learning priorities, often concerning issues that are overarching for (parts) of the school. Individual decision contexts may result from teachers' perceptions of knowledge and skills gaps concerning emerging classroom needs or externally developed knowledge (Hashweh, 2003). 
Previous studies have considered teacher motivations for PD (e.g., Jansen in de Wal et al., 2014; Kwakman, 2003; Thoonen et al., 2011; Van Eekelen et al., 2006; Vermunt \& Endedijk, 2011), as well as teacher involvement in school decision-making (Scribner et al., 2007; Smylie, 1992). However, the impact of different decision contexts on PD motivations has not been studied empirically. Schibeci and Hickey (2004) and Clark et al. (2012) have pointed out the importance of teacher autonomy in PD decisions for teacher motivations. Jansen in de Wal et al. (2014) concluded that freedom of PD choice for teachers enhances their feelings of autonomy, thus enhancing their motivation for PD; however, decision context was not a condition in their study.

Research concerning reform-driven PD shows that unless it leaves room for teacher input, it risks being rejected (Avidov-Ungar, 2016; Wallace \& Priestly, 2011). Hargreaves (2003) stresses the detrimental motivational consequences of reform-driven PD that involves "a strong insistence on performance standards and prescribed classroom techniques" (p. 176). Nir and Bogler (2008) note that Local Educational Authorities are seen by teachers as bodies too remote from day-to-day educational practice to make sensible PD decisions. Kennedy (2016) states that mandatory participation in teacher PD makes for much lower learning outcomes in teacher PD.

\subsection{Research concerning teaching experience and (motivation for) participation in PD}

The relationship between teaching experience or teacher age and PD has been the subject of a body of research. Many of these studies (e.g., Philipp \& Kunter, 2013; Richter et al., 2011), make use of the career stages model of Huberman et al. (1993). Five ideal-typical stages that describe the development of teachers from novice to end-of-career (survival and discovery; stabilisation; experimentation/activism and stocktaking; serenity and conservatism; disengagement) are used in PD research to explain motivation, actual participation, or preference for various types of PD content.

Maskit (2011) proposes a curvilinear relationship between career phase and attitudes towards external educational reform programmes: in the induction phase and the career-frustration and winddown phases, positive attitudes are lower than in the middle phases of competency building, enthusiasm and growth, and stability. Richter et al. (2011) come to similar conclusions. Their data show a curvilinear relationship between age and participation in in-service training courses. However, they discovered that older teachers invest less in collaboration and more in reading. The assumption that teachers' PD participation decreases in the last third of their career (cf. Day \& Gu, 2007) may obscure this move from formal and collaborative to informal and individual PD activities.

In addition to examining participation patterns in $\mathrm{PD}$, research has also focused on learning needs and preferred PD subjects in teacher careers. Cochran-Smith and Lytle (1999) conclude that in $\mathrm{PD}$, novice teachers seek new knowledge for practice, in order to become more effective teachers, while experienced teachers value knowledge of practice. Kyndt et al. (2016) found that novice teachers (1-3 years) have more motivation for PD, and are more interested in knowledge and skills with direct applicability to their own classroom. More experienced teachers showed lower levels of motivation for $\mathrm{PD}$, and concentrated more on learning new teaching methods and changing teaching and learning beliefs.

In summary, some career models concerning teacher PD participation distinguish between novice and more experienced teachers, while others use a three-fold distinction and predict a curvilinear model. These models may reflect participation in formal and collective forms of PD, but risk obscuring participation in other types of PD. These studies are not highly informative when it comes to careerspecific learning needs. We have not found research regarding career stage and PD autonomy, with the exception of Clark et al. (2012, p. 138) who note that significantly more senior than junior teachers perceived degradation of their classroom autonomy. The research reviewed does not permit us to specify expectations regarding teaching experience and PD motivations. 


\subsection{Research questions}

This research is guided by the following research questions:

1. With regard to PD activities among primary teachers, what are the differences and similarities between board/principal, team and individual decision contexts in terms of (positive and negative) affective and cognitive valences (for the school, the student, and the teacher personally) and autonomy (sense of personal autonomy and perceived freedom of action)?

2. What are the differences and similarities in these variables between less and more experienced teachers?

3. How are PD experiences of primary teachers associated with positive and/or negative valences regarding $\mathrm{PD}$ ?

4. How are PD experiences of primary teachers associated with (the role of) autonomy with respect to PD?

\section{Method}

\subsection{Design and sample}

This study was based on a mixed method design. Data collection began in 2014. Teachers in the sample had a minimum of one year's teaching experience. A convenience sample of 441 teachers from 54 primary schools in The Netherlands completed a questionnaire about motivational aspects of their PD participation in different decision contexts. Results of this component of the study have been published elsewhere (de Brabander \& Glastra, 2018). Within each participating school, two teachers were approached for interviews, resulting in a sample of 96 teachers. Interviewees were recruited on a voluntary basis from among each school's questionnaire respondents. One teacher with predominantly remedial teaching tasks was removed from the sample. Of this sample of 95 interviewees, $81.6 \%$ were female and $19.4 \%$ were male; $M(S D)$ age $=41.01$ (11.01), with a range of 22 to 63 years; $M(S D)$ teaching experience $=14.09$ (9.03) with a range of 2 to 41 years. Both age and teaching experience had a bimodal distribution, with modes at 31 and 50 years (age) and 11 and 34 years (teaching experience). Gender and age data show a reasonable match with official Dutch primary teacher population statistics $(M$ population age $=43.04$ years, $83.7 \%$ female teachers; Stamos, 2013). Although sample characteristics showed a reasonable fit with population characteristics, drawing interviewees on a voluntary basis from survey respondents per school may have had the effect of selecting teachers who were particularly motivated to share their PD experience.

\subsection{Procedure}

Teachers were interviewed at their schools by pre-master students of Education and Child Studies at Leiden University. Interviewers received training. Teachers were told that the interviews would centre on their PD experiences. Interviews lasted 30-45 minutes and were recorded. Given that interviewing respondents about all three decision contexts would take too much time, each interviewee was pre-assigned two decision contexts, in such a way that the overall frequency of each decision context being probed would be equal. However, some of the respondents turned out not to have relevant experience in one of the decision contexts assigned to them, which necessitated some last-minute adaptations of decision contexts; nevertheless, the three decision contexts were investigated in almost equal measure. The interviews were transcribed verbatim and imported into ATLAS.ti for further analysis. 
In some cases, it proved difficult to distinguish between decision contexts; for instance, when board decisions were perceived by individual teachers or teams as their own decisions, or when memories regarding the locus of decision-making were not clear. In each case, we tried to reconstruct which decision context was concerned, but some errors in the categorisation of cases may have arisen.

\subsection{Instruments}

In the semi-structured interview, respondents were first asked to describe their PD activities over the last two years and to indicate whether their participation was decided by themselves, their team, or the school board. Respondents were then interviewed about a PD activity of their own choice for each of the two decision contexts assigned to them. The interviewer was instructed to ask for PD experiences. This question was meant to yield insights into both cognitive and affective valences. The question "What consequences has the PD activity had?" was specifically meant to trace cognitive valences. Interviewers were instructed to probe for both positive and negative consequences and for consequences for teachers personally, for students, and for the school. Sense of autonomy was targeted in the question "Did you feel that you were directing your own learning in the PD activity?", and interviewers were instructed to probe for how much room there had been for teachers' initiatives regarding these PD activities.

The decision was taken to use age as a proxy for teaching experience, and to define two age/experience groups using the median as the cut-off point; this decision was prompted by the fact that (a) a division into three teaching experience groups would yield a very uneven distribution (induction $\mathrm{N}=5$, mid-career $\mathrm{N}=75$, end-of-career $\mathrm{N}=9$, unknown $\mathrm{N}=6$ ); (b) both age and teaching experience had bimodal distributions; (c) the relation between age and length of teaching experience was quite strong $(r=.86)$; and (d) teaching experience had far more missing values. After removing four interviewees for whom the exact age was missing, the younger group $(<41$ years) comprised 45 , and the older group ( $\geq 41$ years) comprised 47 teachers.

\subsection{Analysis}

Interviews were coded using ATLAS.ti. Text fragments were coded for (negative and positive) cognitive valence (for the teacher, the student, and the school), (negative and positive) affective valence, and autonomy. Text fragments could be assigned all of the above codes simultaneously. After being trained by the authors, two research assistants coded the interviews. Inter-coder discrepancies were discussed with the authors until consensus was reached. These discussions were guided by definitions of UMTM concepts and occurred mainly in the initial coding stages. As it proved to be difficult to distinguish between a sense of personal autonomy and perceived freedom of action, given that the former often remained latent or implied in the latter, it was decided to code for both under the code "autonomy". Once all interviews were coded, the coded fragments were analysed by the authors in three steps.

The first step in the analysis focused on identifying the presence of codes and combinations of codes across the interviews for each age group and each decision context. Each interviewee could add a score of 1 to the number of code occurrences across interviews, irrespective of their frequency within an individual interview. This number, that is, the number of teachers with a specific code, was then transformed to give the proportion of the total number of teachers per age group who were interviewed about a specific decision context (see Table 1). In this way, the uneven distribution of age groups and decision contexts was corrected for. Co-occurrences indicate semantic associations in statements relating to different codes. Co-occurrences of codes, that is, combinations of codes, were treated likewise. For each combination of codes, we counted the number of teachers to whom that combination of codes was assigned, irrespective of the number of text fragments that were actually tagged with that code combination. This number was then transformed to give the proportion of the total number of teachers per age group who were interviewed about a specific decision context. The proportions of occurrences and co-occurrences are presented in Tables 1 to 6 in the Appendix. With the aid of qgraph 
(Epskamp et al., 2012) these tables were then transformed into code network diagrams (Figure 1) to summarise differences and similarities across decision contexts and age groups. In these diagrams, cooccurrence proportions are indicated by lines between codes that differ both in thickness and density. A proportion of 0 is represented by the absence of a line, a proportion of 1 by a thick, black line. Proportions between these extremes are represented by lines with different thicknesses and different densities (See also Appendix 1, Tables 1 to 6). Differences in code occurrence proportions are indicated by different circle sizes. The exact formula for rendering the circle size was: vsize $=3+10 *$ proportion of code occurrence.

This analysis constitutes an initial, mainly quantitative approach to the interviews. It was also intended to generate research ideas for a further analysis of PD experiences found in the coded text fragments.

Table 1

Distribution of decision contexts across age groups

\begin{tabular}{llll}
\hline & Board context & Team context & Individual context \\
\hline Younger teachers & 34 & 25 & 28 \\
Older teachers & 26 & 34 & 33 \\
\hline
\end{tabular}

In the second step of the analysis, all interview fragments with the same code were reviewed for differences and similarities in experiential content. The question leading this second analytic step was: what were the experiences associated with positive or negative valences, with affective valences, and with feelings of (lack of) autonomy attached to a PD activity? Here, the analysis was not guided by an explicit theory; categorisation followed an inductive, grounded theory approach (Strauss \& Corbin, 1998). Categories were formed based on similarities and differences in experiential content guiding associations with PD valences. As a result of this constant comparison of new experiences with those already attributed to categories (Glaser \& Strauss, 1967, p. 102), the coding process necessitated the adaptation of categories, and categories were thus reformulated. In this way, several categories were further developed (including their definitions), and experiences were incorporated into these categories until all experiences in the interviews pertaining to codes had been analysed (see categories and text fragment examples in the Appendix). To enhance trustworthiness, the fit of all coded text fragments with category definitions was checked. Additionally, the associations of the experiences in each category with decision contexts and age groups were examined to discover specific patterns. Finally, an overview of core categories, definitions, and text examples associated with valences and autonomy was produced (see Appendix).

The third step concerned a reflection on the data thus analysed, from the perspective of teachers' broadly shared attitudes to PD in the context of teaching as a profession and the working conditions that govern primary education.

\section{Results}

In this initial, quantitative part of the analysis, we present codes and code co-occurrences in code networks organised by age group and decision context. In the second part of this section, we will focus on the qualitative analysis of PD experiences in coded text fragments. 


\subsection{Quantitative patterns of codes and co-occurrences}

Table 2 presents an overview of the codes used in the analysis and their meanings. Figure 1 depicts the presence of codes and co-occurrences for each age group and decision context. All these patterns constitute interaction effects between age groups and decision contexts. The main differences and similarities between these patterns may be summarised as follows:

1. In the board decision context, there is a difference in the more negative cognitive and affective valences (ncvp, nav) towards PD and a stronger connection between the two for the older teachers compared to the younger teachers (Figure 1: on the right-hand side of the board code networks).

2. There are greater positive valences (pcvp, pcvs, pcvl, pav) of team decisions for the younger teachers compared to the older teachers (Figure 1: team code networks).

3. The age groups are similar in the individual decision context, except for greater importance of negative personal cognitive valences (ncvp) among the younger age group. Together, these last two patterns could point towards a more insecure position of younger teachers, who faced negative consequences of their own PD choices and found protection from negative consequences under team conditions (Figure 1: individual code networks).

4. In all decision contexts, there were no big differences between age groups in the importance of autonomy, nor in its associations (Figure 1: autonomy in all code networks).

5. For the younger teachers, the individual and team contexts showed similar patterns of strong positive cognitive and affective valences (pcvp, pcvl, pcvs, pav) and associations between these codes, while the board condition showed less strong positive valences and associations (Figure 1: left-hand side of code networks in the board context compared to team and individual contexts, for younger teachers).

Table 2

Overview of codes and their meanings

\begin{tabular}{|l|l|l|l|l|l|}
\hline aut & autonomy & pcvp & $\begin{array}{l}\text { positive cognitive valence } \\
\text { personal }\end{array}$ & ncvp & $\begin{array}{l}\text { negative cognitive valence } \\
\text { personal }\end{array}$ \\
\hline pav & $\begin{array}{l}\text { positive affective } \\
\text { valence }\end{array}$ & $p c v s$ & $\begin{array}{l}\text { positive cognitive valence } \\
\text { for the school }\end{array}$ & $n c v s$ & $\begin{array}{l}\text { negative cognitive valence } \\
\text { for the school }\end{array}$ \\
\hline nav & $\begin{array}{l}\text { negative } \\
\text { affective valence }\end{array}$ & pcvl & $\begin{array}{l}\text { positive cognitive valence } \\
\text { for the student (learner) }\end{array}$ & ncvl & $\begin{array}{l}\text { negative cognitive valence } \\
\text { for the student (learner) }\end{array}$ \\
\hline
\end{tabular}

6. For the older teachers, the individual decision context had the most positive and most strongly associated valences, while the board decision context had the most negative personal cognitive and negative affective valences (Figure 1: right- and left-hand side of board code networks compared to individual code networks, for the older age group).

7. For both age groups, the team decision context was the one associated with the least negative consequences and affects (ncvp, nav) (Figure 1: right-hand side of team code networks compared to board and individual code networks, for both age groups).

8. For both age groups, positive affective valences (pav) were more strongly connected to personal cognitive valences (pcvp) in the individual decision context compared to board or team decision contexts (Figure 1: pav for both age groups in individual compared to team and board contexts). 
$<41$ years
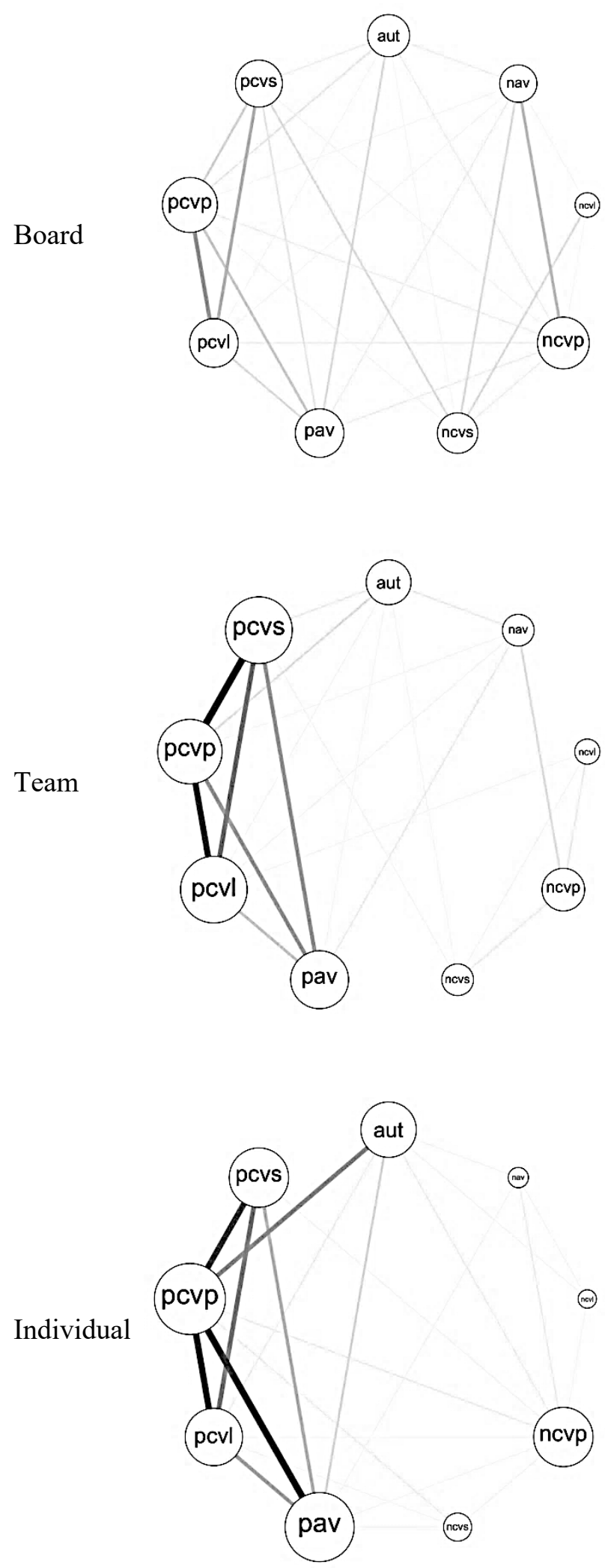

$\geq 41$ years
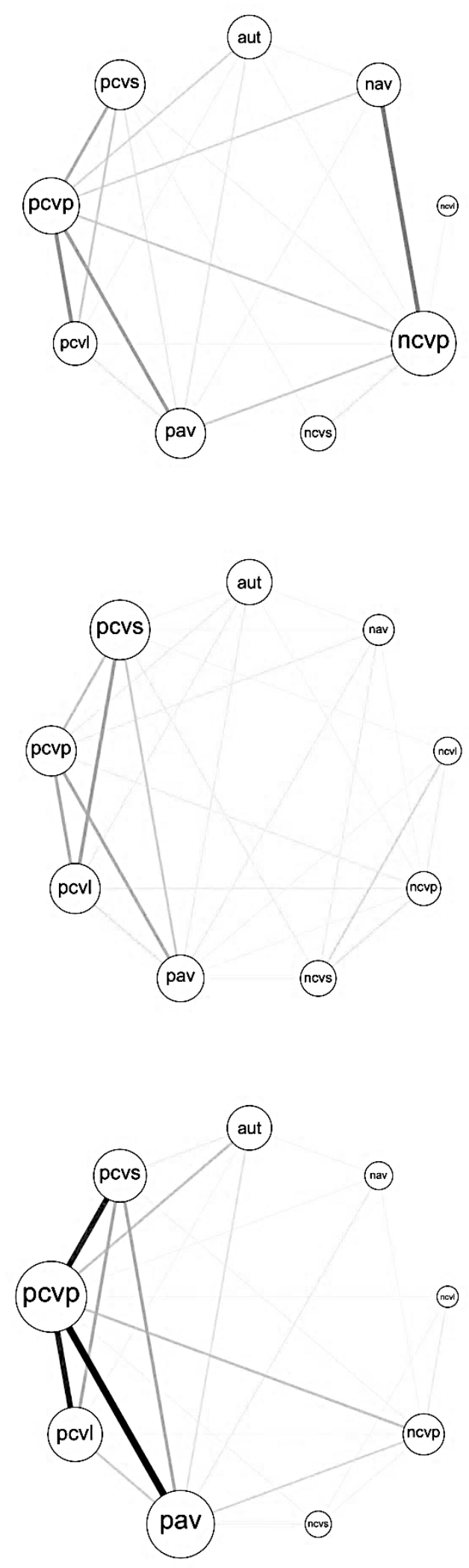

Figure 1. Code occurrences and co-occurrences for different combinations of age and decision context (for legend, see Table 2) 
Analysing text fragments labelled with the autonomy code, we discovered that these fragments could be subdivided into three different sub-codes: positive autonomy, negative autonomy (the negative valuation of sense of personal autonomy or perceived freedom of action regarding PD), and absence of autonomy (the observation that freedom of action in, or a sense of personal autonomy regarding PD, was absent). Further analysis showed that positive autonomy (Figure 2) was far stronger for younger teachers from the board $(20.6 \%)$ through team $(32 \%)$ to individual $(60.7 \%)$ decision contexts, compared to older teachers $(26.9 \% ; 23.5 \% ; 30.3 \%)$. Negative autonomy (Figure 3 ) was, at far lower levels, slightly more present among younger teachers, especially in the team (8\%) and the individual (7.1\%) decision contexts, while older teachers experienced negative autonomy in the board (3.8\%) and the individual (3\%) decision contexts. This may mean that PD that grants greater autonomy causes more discomfort for younger teachers than older teachers. Older teachers perceived the absence of autonomy (Figure 4) far more in the team $(23.5 \%)$ and individual $(18.2 \%)$ decision contexts than younger teachers $(8 \%$, $3.6 \%$ ). This may mean that younger teachers identify more strongly with team decisions and have a stronger tendency to transpose the feelings of autonomy associated with individual decisions about PD onto the PD activity itself.

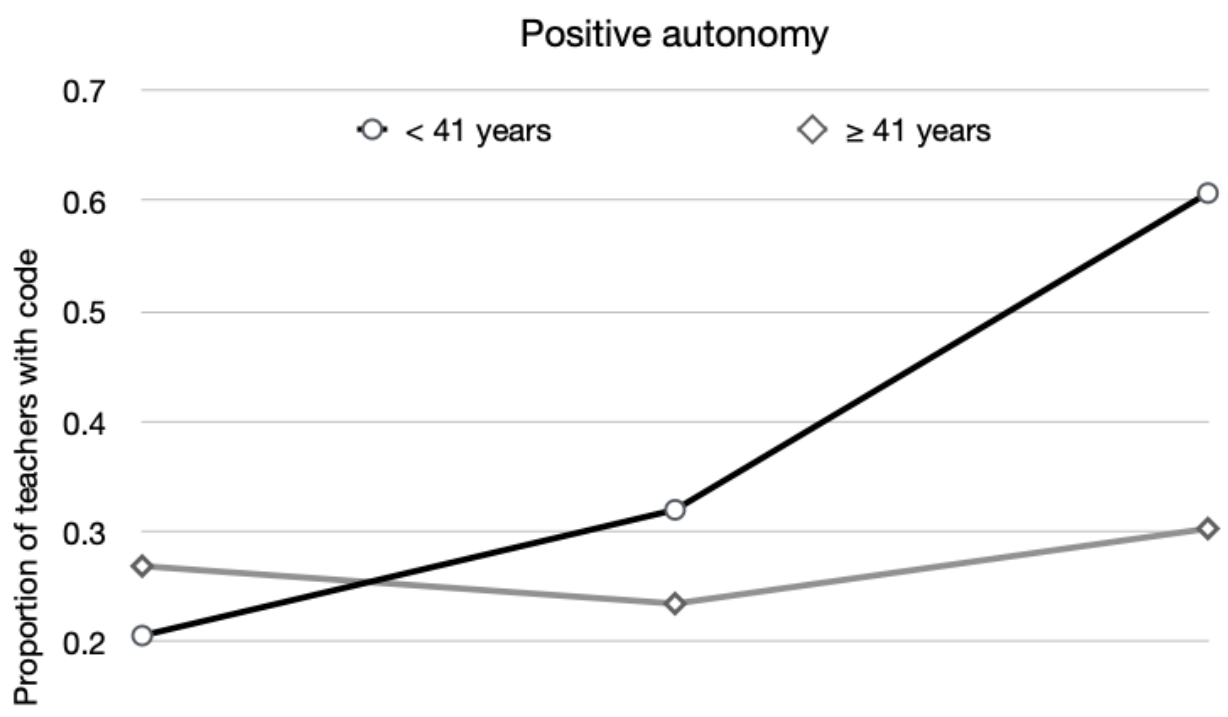

0.1

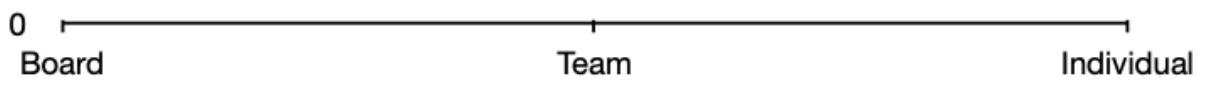

Figure 2. Distribution of positive autonomy codes in age groups and decision contexts 

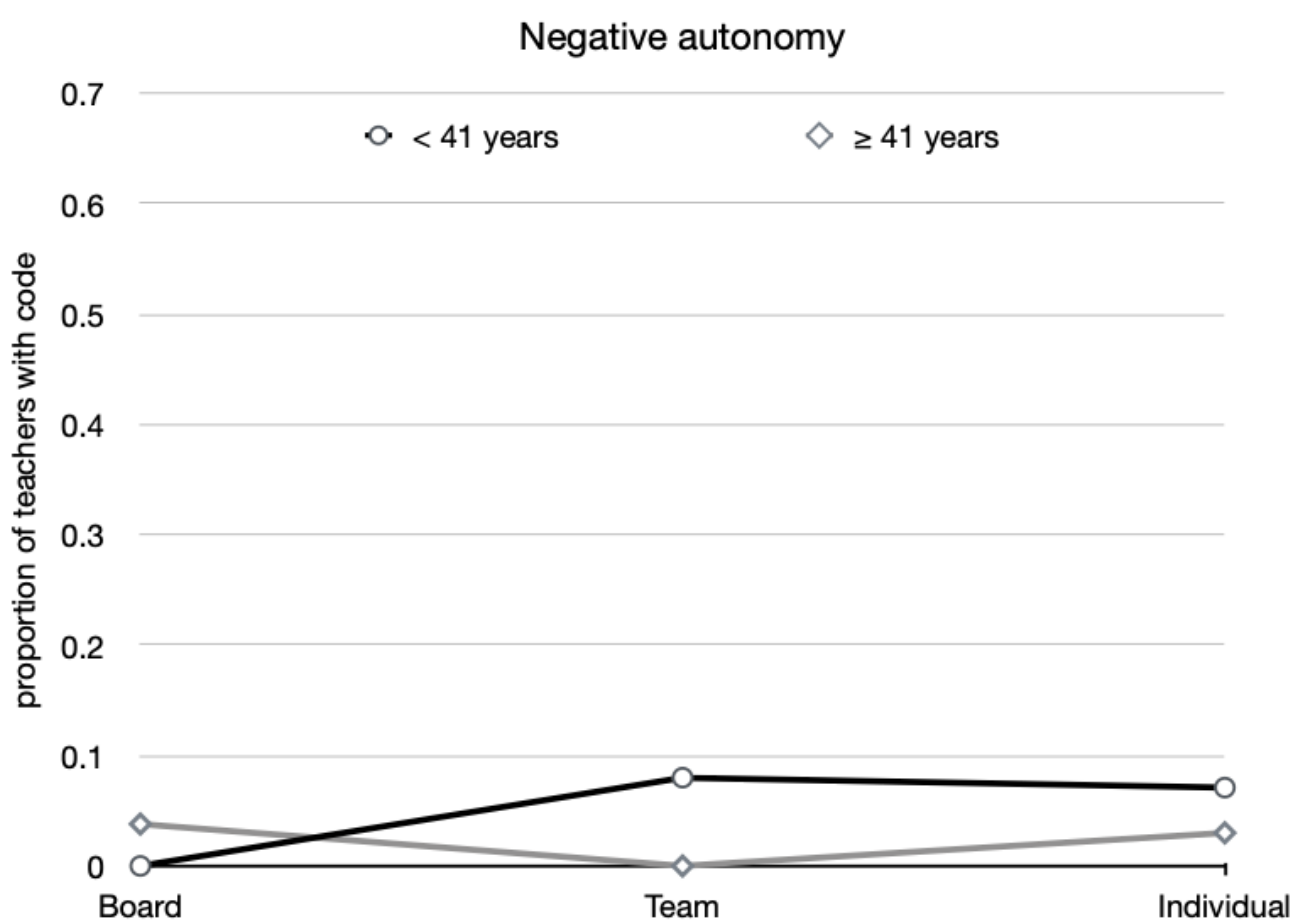

Figure 3. Distribution of negative autonomy codes in age groups and decision contexts

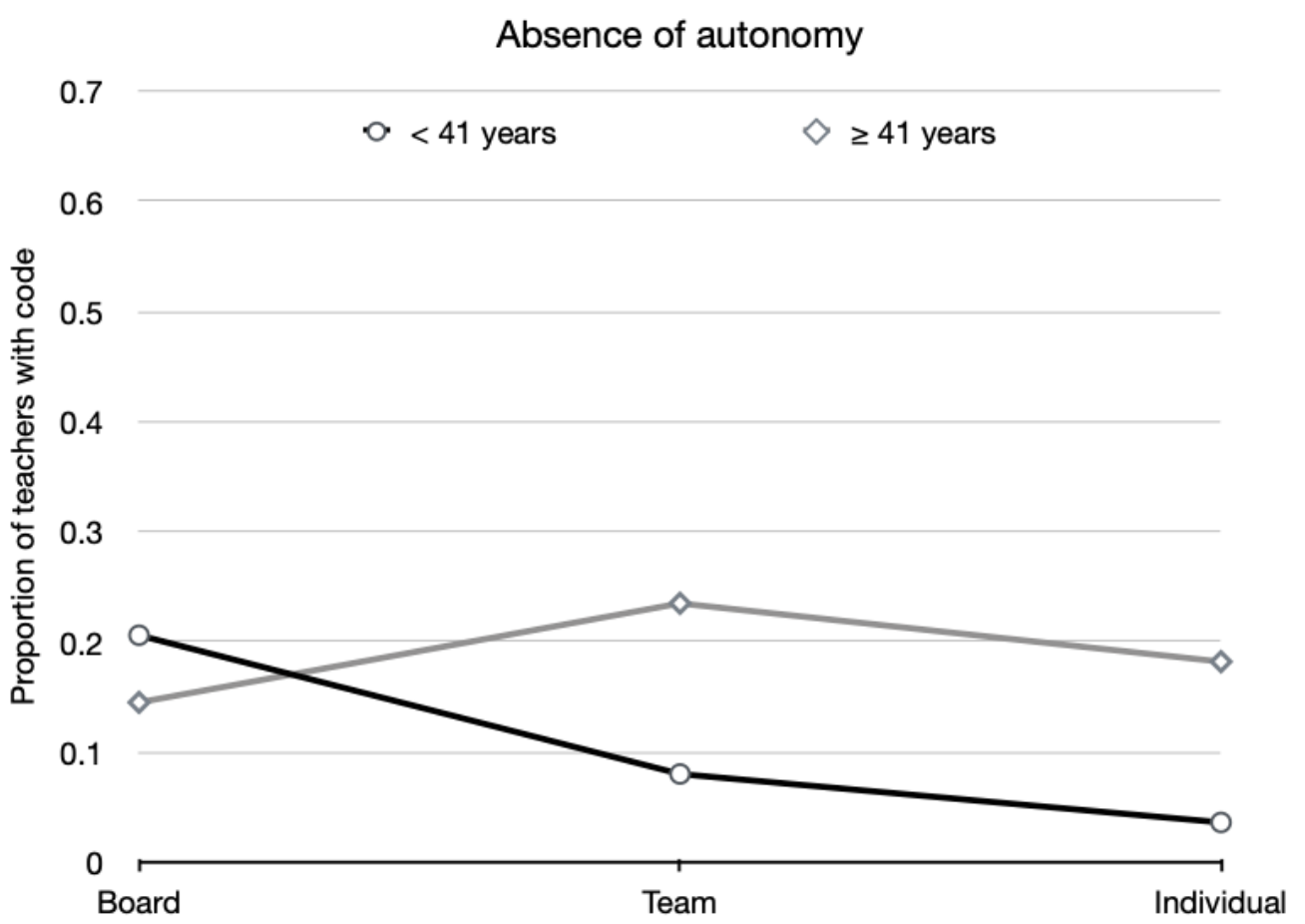

Figure 4. Distribution of absence of autonomy codes in age groups and decision contexts

\subsection{Qualitative patterns in coded text fragments}

In the following qualitative analysis, we address three questions: (a) what is the nature of primary teachers' experiences concerning (their participation in) PD that are coded as having positive and negative valences; (b) what is the nature of primary teachers' statements concerning (the role of) 
autonomy in PD; and (c) as a reflection on the answers to these questions, which elements of a broadly shared attitude impacting teachers' valuations of PD can be found in the coded data? To indicate how our findings relate to the interview texts, each finding is labelled with the respondent's database ID number followed by the number of the text fragment. We have also indicated whether the respondent belongs to the older or the younger teacher group by prefixing this reference with "o" or "y" respectively. Furthermore, the Appendix provides definitions and textual illustrations of the categories presented in the following sections, including citations referred to by respondent/fragment number alone in the following sections.

\subsubsection{Valences}

Further analysis of coded text fragments yielded several broad categories of experiences associated with positive and negative PD valences. First, the school as a decision and work context, with its workloads, routines, colleagues, and leadership, impacts the ways in which PD is experienced by teachers. Second, teachers' valuation of PD is influenced by the particular consequences for stakeholders, such as the students, the school, and the teachers personally. Third, qualities of PD content and design in relation to teachers and their classrooms also informed teachers' PD valuations.

\subsubsection{Context conditions}

Valuations of particular PD decision contexts were transferred onto valuations of PD itself. "We have had plenty of courses, where you wondered: 'What am I doing here?' Courses that you had to sit out. Okay, the school board decided we have to do this course, we'll just sit it out." (y32:16). For many respondents, mandatory participation meant that its contents did not fit with their learning needs or those of their school (o35:19). In the individual context, positive transfer of decision context to PD valences abounded. "The nice thing about it is that you have chosen it yourself, that you're very interested and therefore you're very motivated." (y9:1). Particularly in the individual decision context, teachers chose PD programmes focusing on specific problems faced by children in their classrooms, thus addressing their own perceived professional deficits as well as the learning or behavioural problems of these children (o58:3). While individual decisions resulted mostly in positive and board decisions in negative valuations, PD valuations in the team decision context depended more strongly on the qualities of PD itself and the consequences for stakeholders. As an example of the latter, following the PD programme as a team was valued positively by many teachers for reasons of team building, collective engagement, efficient distribution of tasks, and alignment of the course with team learning needs (y66:8; y82:10).

Fit with workload and work schedule was associated with positive PD valuations. Many teachers disliked PD programmes because they were time-consuming or scheduled at particularly busy times. Behind these negative valuations were arguments in which teaching time was set off against and prioritised over time spent on PD. "A whole day, for me a waste of time, (...) but for the students as well, because it could have been one day more for them to learn something." (y36:16) Here, teachers clearly demonstrated efficiency reasoning, resulting from the experience of time pressures and teaching as a professional priority. "My appreciation of professional development activities is variable. And that depends on whether it concerns an activity that you need at that moment or an activity that you were not specifically looking for at that moment. And that moment may have to do with the fact that you are in the middle of a school report period or preparing for a Christmas musical. It depends greatly on all such things." (o18:18). The (lack of) support from the school principal for PD participation was also mentioned frequently. "I have a principal who stimulates it very much, who likes it when people can function in .. yes, as if on fire, who acknowledges that then the school benefits in a special way." (033:6)

\subsubsection{Stakeholder consequences}

Experiences regarding the consequences of PD for the students, the school, and for teachers themselves impacted PD valuations. Here, greater importance was assigned to students and teachers, often in combination, than to schools. 


\section{Students}

$P D$ was valued positively when it was in the students' best interest according to the teachers. Teachers were satisfied with PD where they felt better equipped to help their students, in the sense of stimulating learning motivations, improving test scores, or diagnosing students' problems. PD was perceived to better help students when it fit students' learning needs and attainment levels more precisely or promised to raise student motivations (092:11) and improve social relations in the classroom. Negative valuations of PD were expressed where teachers felt that it lacked the above qualities or harmed students or classroom relations, or where teachers thought that teaching their students was more useful than participating in PD. Importantly, teachers referred more frequently to "their" students and their "own" classrooms than to the school as an organisation or to the school's students in general.

The fact that only a small proportion of teachers mentioned negative cognitive valences for students is related to the teachers' perception that students would often be largely unaware of PD effects in the classroom (y48:7), to the fact that PD was frequently not implemented in the classroom at all, or to the fact that teachers actively filtered negative consequences to protect their students. In the quantitative results, the co-occurrences between positive cognitive valences for teachers and for students is evident. In many statements, teachers presented themselves as the ones passing positive PD learning and inspiration on to the students. "The better the grasp you have of the subject matter, the more freedom you have in dealing with it. Therefore, you can offer much more to the children. And I am convinced, in fact, that you cannot teach children just because you know things, but because you are inspired, you really love it yourself." (o33:3)

If PD is to be positively valued, it should have perceptible effects for the teacher and the students. "When you really see the effect—so you're doing it and you see, you're pleasantly surprised (...) that you see that it does something for the child and for yourself as well when you see real progress (...). A visible effect, something of a wow factor, what happens now is really cool." (y9:16).

Teachers

Professional growth, addressing knowledge and skills gaps, and becoming more capable of helping students and improving classrooms are experiences that lead to positive valuations of PD. Frequently, witnessing PD effects in children appears to be crucial in generating such experiences. In addition, many teachers referred to personal growth and learning as pleasant and rewarding in itself. "I have also looked at what I like. Because I like to improve my skills, to challenge myself. And I thought, a bit of reading, spelling, dyslexia: there's my challenge." (y3:1).

Acknowledgement of expertise through PD in school and the perception of PD as a career boost also led to positive PD valuations. A teacher who took an autism course experienced positive consequences. "In fact, I was initially given the cold shoulder in this regard by the school's in-house autism specialist, but the school principal stood up for me. That felt good." (o24:19) Lack of acknowledgement or the impossibility of putting PD based expertise to use within the school was also often mentioned. Here, the school context, often the school principal, plays an important role.

School

Teachers saw PD content as relevant if it addressed issues that they and the principal or the board had defined as urgent. PD that enabled teachers to solve such issues was valued positively. The sense of urgency among teachers was especially great following a negative assessment by the Inspectorate of the school's performance on standardised tests. Here, teachers generally indicated that PD participation was necessary and often resulted in removing the threat of school closure. PD effectiveness in these cases was often seen as self-evident, and readiness to participate in PD was without question (y60:1). These cases were an exception to the rule of teachers experiencing a lack of fit of (usually mandatory) PD within board decision contexts. 


\subsubsection{PD qualities}

\section{Immediate applicability of PD}

Most of the teachers stressed the desirability of PD to be immediately applicable in their classroom. "Well, the timing was simply very convenient, and you could do something with it straight away, without having to sort out a lot of things." (o18:2) PD applicability means coherence with prevalent classroom and school situations, as perceived by teachers. A younger teacher stated: "This course referred directly to the group. Each teacher could think of their own group: do I have children in my group that could be involved in this? So yes, that's very practical." (y65:3) Generally, PD lessons that were not put into practice led to negative valuations. "What I disliked was that you had to be patient, that it just took so long before it was implemented. Well, of course, you can be deeply serious yourself, but when your colleague isn't..." (y79:15) Time pressures and school routines were said to limit the applicability of PD (y9:12). Additionally, some teachers expressed an aversion to "theory", which served as a generic term for anything not practical in nature (o70:11). In PD, theory should always be closely tied to practice, according to the respondents. Many of the PD activities originating in government policies implied (perceived) mandatory application. Here, valences depended on judgments about the time investment involved, and on perceived benefits for the students. In general, applicability was attributed to PD in individual and (to a lesser degree) team decision contexts more than in the board contexts. Overall, school boards and the ministry were thought to be too far removed from daily school practice to be able to put PD to appropriate use (y23:12).

\section{Novelty of PD content}

The novelty of the PD content as perceived by teachers was mostly associated with positive valuations. "Sometimes a course disappoints me because there is little new information and because I've been in teaching a long time, of course, and I have taken lots of courses." (o44:1) However, positive valuations were dependent on perceived practicability. When PD served to implement new government policies, teachers often saw it as interfering with tried and tested school routines. "The first time was positive, but then you get courses on 'action-directed teaching' and 'result-oriented teaching', and then you have to change group plans and you are asked to write down more, and most of all to evaluate; you become increasingly negative, you think, we finally have things in good order, and then we have to start changing everything all over again." (o61:4). Particularly older teachers reported experiencing a policy merry-go-round (029:6) and often felt that PD programmes did not acknowledge their professional experience. In these cases, (alleged) novelty was valued negatively.

\section{PD learning arrangements}

Teachers tended to associate their valuations with certain aspects of PD learning arrangements. For many teachers, PD should not be in a lecture format (o11:4), should facilitate the expression of personal experiences and learning needs (y79:6), and should fit with preferred ways of learning, such as working towards clear learning goals specified from the outset (o18:11) or working in small groups and engaging in direct interaction with peers. "And I always find it valuable when other people from other schools participate, they have totally different input. They do things differently and that's very valuable." (o44:1). Learning by doing, allowing room for application and experiment (y17:4), and receiving performance feedback were mentioned especially by younger teachers, who were more inclined to adopt innovations and explore whether they worked for students. "I would have appreciated a follow-up session to discuss the problems that you often encounter. Not only before you actually work with the method." (y52:2) In addition, teachers valued the enthusiasm of those delivering PD (y64:2). In the case of board decisions - and in individual and team decisions too, albeit to a lesser degree- - prepackaged, standardised PD formats increased impressions of lack of fit of PD with teacher learning needs (o35:16; o43:10).

\subsubsection{Valences and age groups}

The quantitative analysis revealed some marked differences between younger and older teachers in terms of positive and negative valences in different decision contexts. Younger teachers seemed more 
inclined to accept PD applications at face value, and to discover the consequences of those applications in the classroom through trial and error (y9:16), rather than deciding beforehand about the usefulness of PD. "I take that lesson on board, I will then try it out with the children, looking at whether it helps more if I do it like this. Well, when you see that it works, you keep using it." (y81:7) Younger teachers were also more inclined to perceive changes in standardised test scores following student-performancetargeted PD as an indication of their own teaching competence (y60:7). In addition, they made use of PD to critically reflect on their own practice and competencies (y65:4), while most older teachers started from a place of confidence in their teaching skills and classroom experience, and used PD to supplement their knowledge and skills.

\subsubsection{Autonomy}

In the interviews, the autonomy code was applied where teachers referred to themselves as steering important aspects of PD or making use of perceived freedom of action related to PD. The coding of sense of personal autonomy proved rather difficult, as it often functioned as a latent theme or was less easily expressed than perceived freedom of action. Nonetheless, the analysis elucidated key features in relation to PD that tend to induce feelings of autonomy or perceptions of freedom among teachers.

When teachers presented themselves as the central steering force in PD activities they had personally organised such activities (y52:5), instructed PD developers, or composed or selected relevant PD elements, or set personal PD goals beforehand. Furthermore, they had decided afterwards which PD knowledge and skills they would and would not bring to their schools, and they actively adapted relevant knowledge and skills to their own teaching practices and school conditions (y48:4). "I think they should show more trust in your professionalism. (...) You will be able to get similar results [to those aimed at by the PD programme] with children if you have an appropriate approach as a teacher. And I do not think that people sitting at their desks know how to do that." (y7:9)

Regarding perceived freedom of action, teachers often mentioned PD that offered a choice of content and activities, or that left room for or even demanded their active input. These options and demands ranged from low-level possibilities (mostly) available during the $\mathrm{PD}$, including the chance to ask questions or to influence the pace (050:5) or time investment involved, to those of a broader, structural nature, such as being able to make a personally or team-appropriate selection of programme elements.

Further analysis of interview fragments with the autonomy code revealed that when teachers perceived themselves as steering their own learning or when they experienced freedom of action within $\mathrm{PD}$, this was almost always valued as a positive aspect of PD. Individual choice of PD was often associated with the perception of positive autonomy in PD. "It was something I had to do for myself, and the school had not really instructed me to do it. So yes, (...) it was in fact 'my thing'." (o30:10) PD in board decision contexts could still lead to positive valuations when teachers perceived elements of autonomy in the curriculum or in the way it engaged them in learning (y17:11-21).

Negative autonomy concerned experiences where teachers felt that the PD gave too much room for personal choice or initiative, thereby jeopardising course coherence. "The course could have been much better. It was rather vague. It was the kind of course where you were very much left to find your own way." (y76:12) "There was plenty of opportunity for contributions, but in the end, they should add up to something, and that was a bit difficult. It seems easier to me when it is clear that this is it, this is what it should be. There was too much room for participant contributions, and those contributions should fit together." (y72:14) These statements seem to express a need for provider-centred PD that does not offer too much opportunity for participant contribution.

The absence of autonomy was associated with teacher statements where autonomy was generally not linked to either positive or negative valuations. Often, this concerned mandatory courses where teachers were obliged to make use of the course content, which was delivered in a fixed format, with no room for self-regulation on the part of the teacher. 


\subsubsection{Broadly shared attitudes}

A reflection on the data analysis thus far also yielded elements of broadly shared attitudes among the respondents towards PD in the context of teaching as a profession and the working conditions that govern primary education. In many cases when teachers evaluated their PD experiences in negative ways, they made use of compensatory mechanisms, the most frequent of which were, firstly, their generally positive attitude towards learning and professional as well as personal development, and secondly, their professional capacity and willingness to learn even under less than favourable conditions (o18:8). Another broadly shared attitude was the view that teaching is an activity that should involve students as directly as possible. In the eyes of many teachers, PD participation often appeared to distract from this professional priority (y36:16). The individual decision context and a degree of autonomy regarding PD proved helpful in increasing the professional priority accorded to PD (see 3.2.2.), but preferably PD should be efficient in delivery and result in practicable knowledge and skills (see 3.2.1.3.). This attitude is reinforced by time pressures experienced by most teachers, who frequently mentioned time-consuming administrative tasks (y9:15). In short, teachers showed a willingness to engage in development, but under the strict condition that PD be efficient and directly applicable.

\section{Discussion}

In this investigation, we established code patterns pertaining to affective and cognitive valences and autonomy among primary teachers concerning PD in board, team, and individual decision contexts, across different teacher age groups. We also examined the nature of primary teachers' experiences in valence and autonomy statements concerning PD.

\subsection{The role of decision contexts in PD valuations}

Our research indicates that decision contexts matter: the individual decision context gives rise to the most positive valences for teachers, and the board context is associated with the most negative valences, while the team context appears to shield most against negative valences. The situational relevance and personal fit of PD in terms of learning needs is particularly important for teachers. School boards and the government are perceived as too distant from classrooms and schools to make relevant and appropriate PD decisions in most cases, which is consistent with earlier research findings (Clark et al., 2012; Locke et al., 2005). Teachers see themselves as best positioned to determine the needs of their classrooms and schools (Clark et al., 2012). Furthermore, autonomy with regard to PD is strong in individual decision contexts and weaker in board contexts.

Our qualitative analysis revealed that teachers were inclined to project the nature of the decision context onto their experience and valuation of the PD activity. The individual decision context may in and of itself lead to positive valences and to the perception of autonomy regarding PD activities. The reverse holds for the board decision context, where positive valences are low, and teachers perceive a lack of autonomy. Nonetheless, the perception of autonomy within PD may limit negative valences even in the case of board decisions.

\subsection{The role of age groups in PD valuations}

Age or length of teaching experience also impacts PD valuations. Older teachers had more negative cognitive and affective valences towards PD in the board decision context than younger teachers. Younger teachers had greater positive valences for PD in team decisions and associated the individual decision context more strongly with negative consequences for themselves. The two age groups were similar in that team decisions shielded them the most from negative consequences. 
We found expressions of positive and negative autonomy and absence of autonomy. Contrary to expectations (Clark et al., 2012), younger teachers scored higher on positive autonomy, but also on negative autonomy (Figure 2): younger teachers felt that too much autonomy led to incoherence in PD. This ambivalent valuation of autonomy in PD may indicate a division within the younger teacher group. Career starters (years 1-6) typically focus on survival and may be insecure about their teaching capabilities (Huberman et al., 1993). Mid-career teachers (years 7-18; Richter et al., 2011) included in our younger group have well-developed teaching and working routines (Philipp \& Kunter, 2013) and appreciate freedom of action in PD. Furthermore, an explanation for the stronger positive autonomy in the younger teachers might be that they experience autonomy where freedom of action is local and relatively restricted, whereas older teachers experience autonomy where they can contribute in more substantial ways to PD. Clark et al. (2012) have pointed out that experiences of younger and older teachers regarding autonomy in their professional work differ. From this perspective, it is also possible that autonomy experiences regarding PD are impacted by the declining levels of professional autonomy that older teachers experience during their careers, while younger teachers enjoy the freedom of action that their classrooms afford them. This aspect certainly merits further investigation.

Our qualitative analysis (3.2.1.4.) showed that older teachers used PD primarily to supplement rather than critically reflect on their skills and knowledge. Based on their more extensive experience, they acted as "gatekeepers", inclined to deciding right away regarding what to take and what not to take from PD into their classrooms. In comparison, younger teachers were more inclined to use PD lessons for critical reflection on their teaching. They were also more inclined to suspend judgment and explore whether PD content worked in their classrooms. This resembles a tendency towards experimentation/activism (Huberman et al., 1993) characteristic of mid-career teachers, who in this study were included in the younger age group.

\subsection{Teacher experiences and valences}

The analysis of experiences of teachers leading to positive and negative PD valuations yielded three broad categories: context conditions, consequences for stakeholders (students, school, and teachers), and PD qualities. Concerning context conditions, we found that the nature of the decision context was often projected onto the PD activity and its consequences. This led to positive valuations mostly in the individual context, and negative valuations mostly in the board decision context. Concerning stakeholder consequences, students and teachers emerged as more important than schools. Above all, to be positively valued, PD needed to be perceived as being in the best interest of students. Direct visibility of PD effects in classrooms helped to ensure this. This finding corresponds with Lortie's observation that teachers look for signs of teaching effect in the present and seek short-term psychic rewards (Lortie, 1975). The teachers in this study viewed professional growth and an improved capacity to help students as the most important contributions of PD. As for PD qualities, the direct applicability of PD content to classroom practices and learning needs stood out. In general, direct applicability was attributed to PD in individual and (to a lesser degree) team decision contexts, rather than in board decision contexts. PD design features such as interactive learning, room for expressing personal experiences, and alignment with preferred ways of learning led to positive valuations. Standardised PD formats enhanced impressions of PD aligning poorly with teacher learning needs. Our findings regarding decision contexts, applicability, and PD format are consistent with Clark et al. (2012, p. 93; also Knight, 2015); however, our investigation points towards the positive influence of autonomy even in mandated $\mathrm{PD}$, and of the team decision context, which produces higher levels of acceptance. Unlike Kyndt et al. (2016) we found no difference between age groups in terms of the importance accorded to the direct applicability of PD. This may be a result of the fact that Kyndt et al. concentrated on informal learning, where autonomy is a defining characteristic and where practicability might be less questionable than in formal types of PD that our interviewees mostly referred to. Moreover, Kyndt et al. used three years' experience as the cut-off point between younger and older teachers. 
There is an important proviso of all of these experiences associated with valuations of PD: many teachers stated that time spent on PD could in many cases be better invested in teaching their students.

\subsection{Teacher experiences and autonomy}

Our research shows that autonomy plays a multifaceted role in teacher experiences with PD. Before the PD activity, autonomy plays a role in influencing PD topics and programming; during PD, it plays a role in active and participative designs; and after PD, it features in the selection and adaptation of PD content for classroom application. When teachers perceived themselves as steering their own learning or when they experienced freedom of action in PD, this was almost always valued as a positive aspect of PD. Selecting and adapting PD outcomes was mostly reserved for instances where teachers doubted the fit of PD. In line with the general appreciation of direct applicability, the valuations of adapting PD for classroom purposes were only positive when deemed cost-effective and efficient. Van Duzor (2011, p.364) points out that "teachers are professionals who use their understanding of innovations, their classrooms, and their personal goals to impact transfer from PD to the classroom." Our research shows that this impact is dependent on the experience of autonomy in PD and a preference for direct applicability.

Negative autonomy related to experiences where PD gave too much room for personal choice or initiative according to teachers (particularly the younger group), thereby jeopardising course coherence.

Teachers frequently related the role of autonomy regarding PD to benefits for "their own" classroom or students. Where professional autonomy of teachers is confined to their own classroom autonomy (Clark et al., 2012), overarching and innovative learning in PD may be at risk.

\subsection{Effective teacher PD: design features versus decision contexts}

As to the discussion about effective teacher PD (Borko, 2004; Clark, et al., 2012; DarlingHammond \& Richardson, 2009; Desimone, 2009; Garet et al., 2001; Penuel et al., 2007), it can be concluded that certain design features (such as interactive learning and active use of teacher experience) are associated with positive valences and experiences of autonomy. However, the overriding importance attached to the direct applicability of PD makes it clear that design features can never determine effective PD independent of situational learning needs, school contexts, and the teachers involved. This underscores Van Duzor's (2011) conclusion that the transfer of PD to classrooms cannot be achieved without the transformative potential and situational insight of teachers. Moreover, the impact of decision contexts on valuations of PD programmes irrespective of their particular design features, and the association of positive autonomy with teacher influence on content and format of PD provision point more strongly towards decision context as a precondition for effective PD (Kennedy, 2016; Schibeci \& Hickey, 2004). The most important background here is the fact that teachers see themselves as best placed to judge what constitutes relevant PD. Nir and Bogler (2008, p. 384) conclude "that teachers' satisfaction is likely to prevail when supervisory processes are constructed and designed to serve teachers' actual needs rather than to meet procedural requirements determined by higher-level bureaucrats, often presenting schools with top-down programmes." In our study, the confidence of teachers in their own judgment regarding the relevance of PD is not to be taken as an expression of pure professional autonomy, since it also reflects teachers' short-term efficiency considerations. Kennedy et al. $(2008$, p. 415) note a similar tendency among teachers who "tend to value more formal, structured CPD opportunities. This view would tend to suggest that teachers favour a more managerial conception of professionalism, aligning with a discourse of efficiency and accountability." In sum, our findings demonstrate that questions of effective PD cannot be fruitfully discussed without recourse to decision contexts that govern PD participation. 


\subsection{Direct applicability and PD efficiency: attitudes of teachers}

Our study revealed several elements of broadly shared attitudes concerning PD. Teachers showed a general willingness and sense of professional duty to develop their skills through PD to serve their students. Together with the experience of some degree of autonomy regarding PD, this had a compensatory effect in cases of PD that felt inadequate to teachers. However, given a strong preference for teaching duties and direct interaction with their students, PD was frequently seen as being a noncore task which could only be positive under the strict conditions of efficiency and direct applicability. Possible selection bias towards teachers with positive PD motivations (see Section 2.1) may have manifested in the positive learning orientation of the teachers in our sample. However, it has certainly not translated into uncritical acclaim of PD courses taken. The applicability criterion refers to teachers being able to imagine new skills or knowledge aligning smoothly with their everyday teaching practices (Knight, 2015). This implies that applicable PD must show a reasonable fit with existing practices and therefore cannot be (too) inconclusive as to its short-term effects, or (too) innovative. Hence, direct applicability seems to be an inherently conservative criterion that embraces small change but keeps more fundamental innovation at bay. Shulman (2004) has characterised the conservatism of schools as an elastic cord pulling teachers back to existing practices. Here, we see that the general attitudes of teachers themselves can form that cord. The appreciation of direct applicability and efficient delivery of PD was also associated with the increase in administrative tasks. Carstensen et al. (1999) have argued that when time is perceived as expansive, people are able to focus on knowledge goals, even when these imply emotional costs or a delay of emotional rewards. However, when time is perceived to be limited, as is the case for teachers, a focus on the present is induced, which is "likely to involve goals related to feeling states, deriving emotional meaning, and experiencing emotional satisfaction" (p. 167). If the applicability and efficiency demands among teachers are indeed (also) driven by this kind of limitedtime perspective and its associated quest for affective need fulfilment (Lortie, 1975), this would not be conducive to deep changes in teachers' knowledge or teaching practices. Teacher demands for PD with direct applicability may be an expression of what Clark et al. (2012, p. 103) have called survival or "reactive learning", and may constitute a danger to deep-level and inquisitive learning among teachers (cf. Biesta et al., 2015; Nir \& Bogler, 2008).

\subsection{Concluding remarks}

Future research should aim to shed more light on which forces underlie the dominance of applicability and efficiency. The current study has found evidence of a strong focus on the visible effects of PD lessons among students. According to Lortie (1975), this focus results from insecurity among teachers regarding their contribution to student development. This may be one of the immediate forces at play; however, other forces must also be considered, such as the workload of primary teachers, the dominant trend in PD towards short, off-the-shelf, packaged courses, and the general accountability culture with its emphasis on efficiency and effectiveness. Therefore, positive valences attached to PDenhanced by individual choice, the experience of autonomy, efficient delivery, or perceived applicability - can not be considered intrinsically good, and should therefore not be targeted instrumentally to increase PD motivations. Our research highlights how teachers' motivations to engage in PD is shaped by the educational field as a system of rules, interdependencies and power relations between educational agents. Given the implied risk of restricting PD to only that which is directly applicable in practice, this impact should be tackled head-on in future research. A fruitful starting point would be Pierre Bourdieu's field theory, in particular the concept of habitus, i.e., the feeling for practice that teachers develop while working in the educational field under the influence of the rules and structures of that field (Bourdieu, 1990). Teachers experience teaching and PD within a field that puts a premium on cost-effectiveness and efficiency and holds schools and teachers accountable for performance outcomes (Gewirtz et al., 2019). Increasing existing forms of motivation may inadvertently strengthen this logic, including where it will result in undesirable consequences for teaching practices. Greater vision regarding the educational field, including teaching practices and the provision of PD, is 
required to determine the practical consequences of the motivation patterns found in our analysis (cf. Biesta et al., 2015). This study has demonstrated that decision contexts and teaching experience will be important building blocks in such an endeavour.

\section{Keypoints}

- The literature on effective teacher professional development (PD) stresses the importance of design features such as active learning arrangements, coherence with teacher beliefs and the external reform context, and collective participation. Our research reveals the crucial influence of a factor overlooked in the literature, namely decision contexts. Who decides about teacher participation in professional development, the school board, the team, or the individual teacher, impacts teacher motivation.

- The main criterion for judging PD relevance is direct applicability to classrooms. Individual decision contexts and autonomy regarding PD both play an important role in ensuring such applicability. The dominance of direct applicability for evaluating PD was not motivated by student or school interests alone; it was also based in a logic of efficiency among primary teachers, which reflected growing work pressures and an accountability culture.

- Among older teachers, teaching experience informed the selection of which PD content to transfer to their classrooms. Younger teachers were more inclined to first explore whether PD worked in their classrooms before deciding about adoption.

\section{References}

Apple, M. W., \& Jungck, S. (1990). "You don't have to be a teacher to teach this unit": Teaching, technology and gender in the classroom. American Educational Research Journal, 27, 227-251.

Ajzen, I., \& Fishbein, M. (2008). Scaling and testing multiplicative combinations in the expectancyvalue model of attitudes. Journal of Applied Social Psychology, 38, 2222-2247. https://doi.org/10.1111/j.1559-1816.2008.00389.x

Avidov-Ungar, O. (2016). A model of professional development: Teachers' perceptions of their professional development. Teachers and Teaching, 22(6), 653-669. https://doi.org/10.1080/13540602.2016.1158955

Ball, S. J. (2003). The teacher's soul and the terrors of performativity. Journal of Education Policy, 18, 215-228. https://doi.org/10.1080/0268093022000043065

Ball, D. L., \& Cohen, D. K. (1999). Developing practice, developing practitioners: Toward a practicebased theory of professional education. Teaching as the learning profession: Handbook of policy and practice, 1, 3-22.

Ballet, K., \& Kelchtermans, G. (2008). Workload and willingness to change: Disentangling the experience of intensification. Journal of Curriculum Studies, 40, 47-67. https://doi.org/10.1080/00220270701516463

Bandura, A. (1997). Self-efficacy: The exercise of control. New York: W. H. Freeman \& Co.

Biesta, G., Priestley, M., \& Robinson, S. (2015). The role of beliefs in teacher agency. Teachers and Teaching, 21(6), 624-640. https://doi.org/10.1080/13540602.2015.1044325

Borko, H. (2004). Professional development and teacher learning: Mapping the terrain. Educational Researcher, 33(8), 3-15.

Borko, H., Elliott, R., and Uchiyama, K. (2002). Professional development: a key to Kentucky's educational reform effort. Teaching and Teacher Education, 18, 969-987. https://doi.org/10.1016/S0742-051X(02)00054-9 
Bourdieu, P. (1990). The Logic of Practice, translated by Richard Nice. Stanford, Calif.: Stanford University Press.

Carstensen, L. L., Isaacowitz, D. M., \& Charles, S. T. (1999). Taking time seriously: A theory of socioemotional selectivity. American Psychologist, 54(3), 165-181. https://doi.org/10.1037/0003-066X.54.3.165

Carver, C. S. (2006). Approach, avoidance, and the self-regulation of affect and action. Motivation and Emotion, 30, 105-110. https://doi.org/10.1007/s11031-006-9044-7

Clark, R., Livingstone, D. W., \& Smaller, H., Eds. (2012). Teacher learning and power in the knowledge society. Rotterdam, Netherlands: Sense.

Cochran-Smith, M., \& Lytle, S. (1999). Relationships of Knowledge and Practice: Teacher Learning in Communities. Review of Research in Education, 24, 249-305. https://doi.org/10.3102/0091732X024001249

Darling Hammond, L. (2005). Teaching as a profession: Lessons in teacher preparation and professional development. Phi Delta Kappan, 87(3), 237-240.

Darling Hammond, L, \& Richardson, N. (2009). Teacher learning: What matters? Educational Leadership, 66(5), 46-53.

Day, C., Elliot, B., \& Kington, A. (2005) Reform, Standards and Teacher Identity: Challenges of Sustaining Commitment. Teaching and Teacher Education, 21, 563-577. https://doi.org/10.1016/j.tate.2005.03.001

Day, C, \& Gu, Q. (2007). Variations in the conditions for teachers. Oxford Review of Education, 33(4), 423-443. https://doi.org/10.1080/03054980701450746

de Brabander, C. J., \& Glastra, F. J. (2018). Testing a unified theory of task-specific motivation: How teachers appraise three professional development activities. Frontline Learning Research, 6 , 54-76. https://doi.org/10.14786/flr.v4i2.342

de Brabander, C. J., \& Glastra, F. J. (2021). The unified model of task-specific motivation and teachers' motivation to learn about teaching and learning supportive modes of ICT use. Education and Information Technologies, 26, 393-420. https://doi.org/10.1007/s10639-020-10256-7

de Brabander, C. J., \& Martens, R. L. (2014). Towards a unified theory of task-specific motivation. Educational Research Review, 11, 27-44. https://doi.org/10.1016/j.edurev.2013.11.001

de Brabander, C. J., \& Martens, R. L. (2018). Empirical exploration of a unified model of task-specific motivation. Psychology, 9, 540-560. https://doi.org/10.4236/psych.2018.94033

Desimone, L M. (2009). Improving impact studies of teachers' professional development: Toward better conceptualizations and measures. Educational Researcher, 38(3), 181-199. https://doi.org/10.3102/0013189X08331140

Devos, G, Tuytens, M, \& Hulpia, H. (2014). Teachers' organizational commitment: Examining the mediating effects of distributed leadership. The American Journal of Education, 20, 205-231. $0195-6744 / 2014 / 12002-0003 \$ 10.00$

Eccles, J. S., \& Wigfield, A. (2020). From expectancy-value theory to situated expectancy-value theory: A developmental, social cognitive, and sociocultural perspective on motivation. Contemporary Educational Psychology, 61. https://doi.org/10.1016/j.cedpsych.2020.101859

Elliot, A. J. (2006). The hierarchical model of approach-avoidance motivation. Motivation and Emotion, 30, 111-116. https://doi.org/10.1007/s11031-006-9028-7

Elliot, A. J., \& Church, M. A. (1997). A hierarchical model of approach and avoidance achievement motivation. Journal of Personality and Social Psychology, 72, 218-232. https://doi.org/10.1037/0022-3514.72.1.218

Emo, W. (2015). Teachers' motivations for initiating innovations. Journal of Educational Change, 16(2), 171-195. https://doi.org/10.1007/s10833-015-9243-7

Epskamp, S., Cramer, A. O. J., Waldorp, L. J., Schmittmann, V. D., \& Borsboom, D. (2012). Qgraph: Network visualizations of relationships in psychometric data. Journal of Statistical Software, 48(4), 1-18. https://doi.org/10.18637/jss.v048.i04 
Evans, L. (2014). Leadership for professional development and learning: Enhancing our understanding of how teachers develop. Cambridge Journal of Education, 44(2), 179-198. https://doi.org/10.1080/0305764X.2013.860083

Fox, R. K., Muccio, L. S., White, C. S., \& Tian, J. (2015). Investigating advanced professional learning of early career and experienced teachers through program portfolios. European Journal of Teacher Education, 38(2), 154-179. https://doi.org/10.1080/02619768.2015.1022647

Garet, M. S., Porter, A. C., Desimone, L., Birman, B. F., \& Yoon, K. S. (2001). What makes professional development effective? results from a national sample of teachers. American Educational Research Journal, 38(4), 915-945. https://doi.org/10.3102/00028312038004915

Gewirtz, S., Maguire, M., Neumann, E., \& Towers, E. (2019). What's wrong with 'deliverology'? Performance measurement, accountability and quality improvement in English secondary education, Journal of Education Policy, 36(4), 504-529. https://doi.org/10.1080/02680939.2019.1706103

Glaser, B. G., \& Strauss, A. L. (1967). The discovery of grounded theory: Strategies for qualitative research. Chicago IL: Aldine.

Hall, C., \& Noyes, A. (2009). New regimes of truth: The impact of performative school self evaluation systems on teachers' professional identities. Teaching and Teacher Education, 25(6), 850-856. https://doi.org/10.1016/j.tate.2009.01.008

Hardy, I., \& Lingard, B. (2008). Teacher professional development as an effect of policy and practice: A bourdieuian analysis. Journal of Education Policy, 23, 63-80. https://doi.org/10.1080/02680930701754096

Hargreaves, A. (2003). Teaching in the knowledge society: Education in the age of insecurity. New York and London: Teachers College Press.

Hashweh, M. Z. (2003). Teacher accommodative change. Teaching and Teacher Education, 19(4), 421434. https://doi.org/10.1016/S0742-051X(03)00026-X

Hawley, W., \& Valli, L. (1999). The essentials of effective professional development: A new consensus. In L. Darling-Hammond \& G. Sykes (Eds.), Teaching as the learning profession: Handbook of policy and practice (pp.127-150). San Francisco: Jossey-Bass.

Hochberg, E. D., \& Desimone, L. M. (2010). Professional development in the accountability context: Building capacity to achieve standards. Educational Psychologist, 45(2), 89-106. https://doi.org/10.1080/00461521003703052

Huberman, M. (1989). The professional life cycle of teachers. Teachers College Record, 91, 31-57.

Huberman, M., Gronauer, M.-M., \& Marti, J. (1993). The lives of teachers. London: Cassell.

Jansen in de Wal, J., den Brok, P. J., Hooijer, J. G., Martens, R. L., \& van den Beemt, A., (2014). Teachers' engagement in professional learning: Exploring motivational profiles. Learning and Individual Differences, 36, 27-36. https://doi.org/10.1016/j.lindif.2014.08.001

Karsten, S. (1999). Neoliberal education reform in the Netherlands. Comparative Education, 35(3), $303-$ 317. https://doi.org/10.1080/03050069927847

Kennedy, A., Christie, D., Fraser, C., Reid, L., McKinney, S., Welsh, M., Wilson, A., \& Griffiths, M. (2008). Teacher learning: Key informants' perspectives on teacher learning in Scotland. British Journal of Educational Studies, 56(4), 400-419. https://doi.org/10.1111/j.1467$\underline{8527.2008 .00416 . \mathrm{x}}$

Kennedy, M. M. (2016). How does professional development improve teaching? Review of Educational Research, 86(4), 945-980. https://doi.org/10.3102/0034654315626800

Knight, R. (2015). Postgraduate student teachers' developing conceptions of the place of theory in learning to teach: 'more important to me now than when I started'. Journal of Education for Teaching, 41(2), 145-160. https://doi.org/10.1080/02607476.2015.1010874

Krapp, A. (2005). Basic needs and the development of interest and intrinsic motivational orientations. Learning and Instruction, 15(5), 381-395. doi.org/10.1016/j.learninstruc.2005.07.007

Kwakman, K. (2003). Factors affecting teachers' participation in professional learning activities. Teaching and Teacher Education, 19(2), 149-170. https://doi.org/10.1016/S0742$\underline{051 X(02) 00101-4}$ 
Kyndt, E., Gijbels, D., Grosemans, I., \& Donche, V. (2016). Teachers' Everyday Professional Development Mapping Informal Learning Activities, Antecedents, and Learning Outcomes. Review of Educational Research, 86(4), 1111-1150. https://doi.org/10.3102/0034654315627864

Leithwood, K., Steinbach, R., \& Jantzi, D. (2002). School leadership and teachers' motivation to implement accountability policies. Educational Administration Quarterly, 38(1), 94-119. https://doi.org/10.1177/0013161X02381005

Little, J. W. (1993). Teachers' professional development in a climate of educational reform. Educational Evaluation and Policy Analysis, 15, 129-151.

Little, J. W. (2006). Professional community and professional development in the learning-centered school. Arlington, VA: Education Association National.

Little, J. W., \& Bartlett, L. (2010). The teacher workforce and problems of educational equity. Review of Research in Education, 34, 285-328. https://doi.org/10.3102/0091732X09356099

Locke, T., Vulliamy, G., Webb, R., et al. (2005). Being a 'professional' primary school teacher at the beginning of the 21st century: A comparative analysis of primary teacher professionalism in New Zealand and England. Journal of Education Policy, 20, 555-581. https://doi.org/10.1080/02680930500221784

Lortie, D. (1975). Schoolteacher. A Sociological Study. Chicago: University of Chicago Press.

Maskit, D. (2011). Teachers' attitudes toward pedagogical changes during various stages of professional development. Teaching and Teacher Education, 27(5), 851-860. https://doi.org/10.1016/j.tate.2011.01.009

Meyers, B., Meyers, J., \& Gelzheiser, L. (2001). Observing leadership roles in shared decision making: A preliminary analysis of three teams. Journal of Educational and Psychological Consultation, 12(4), 277-312. https://doi.org/10.1207/S1532768XJEPC1204 01

Milner, H. R. (2013). Policy reforms and de-professionalization of teaching. Boulder, CO: National Education Policy Center. Retrieved from http://nepc.colorado.edu/publication/policy-reformsdeprofessionalization

Ministerie van OCW (2012). Nota Werken in het Onderwijs 2012. [Memorandum Working in the field of education] The Hague, The Netherlands: Ministerie van OCW.

Moore, A., Edwards, G., Halpin, D., \& George, R. (2002). Compliance, resistance and pragmatism: The (re) construction of schoolteacher identities in a period of intensive educational reform. British Educational Research Journal, 28(4), 551-565. https://doi.org/10.1080/0141192022000005823

Nir, A., \& Bogler, R. (2008). The antecedents of teacher satisfaction with professional development programs. Teaching and Teacher Education, 24(2), 377-386. https://doi.org/10.1016/j.tate.2007.03.002

Onderwijsraad (2005). Kwaliteit en inrichting van de lerarenopleidingen. Briefadvies aan de Tweede Kamer [Quality and organisation of teacher education. Advice letter to the Lower House of Parliament]. Den Haag: Onderwijsraad.

Onderwijscoöperatie (2016). De staat van de leraar 2016. [The state of the teacher 2016] Retrieved from http://www.fvov.nl/wp-content/uploads/2016/04/W-20160413-Staat_van_de_leraar.pdf

Pearson, L. C., \& Moomaw, W. (2006) Continuing validation of the Teaching Autonomy Scale. The Journal of Educational Research, 100(1), 44-51, https://doi.org/10.3200/JOER.100.1.44-51

Peetsma, T. (2000). Future Time Perspective as a Predictor of School Investment. Scandinavian Journal of Educational Research, 44(2), 177-192. https://doi.org/10.1080/713696667

Penuel, W. R., Fishman, B. J., Yamaguchi, R., \& Gallagher, L. P. (2007). What makes professional development effective? Strategies that foster curriculum implementation. American Educational Research Journal, 44, 921-958. https://doi.org/10.3102/0002831207308221

Philipp, A., \& Kunter, M. (2013). How do teachers spend their time? a study on teachers. Teaching and Teacher Education, 35, 1-12. doi.org/10.1016/j.tate.2013.04.014

Reay, D. (2015). Habitus and the psychosocial: Bourdieu with feelings. Cambridge Journal of Education, 45(1), 9-23. https://doi.org/10.1080/0305764X.2014.990420 
Reeve, J., Nix, G., \& Hamm, D. (2003). Testing models of the experience of self-determination in intrinsic motivation and the conundrum of choice. Journal of Educational Psychology, 95, 375392. https://doi.org/10.1037/0022-0663.95.2.375

Research voor Beleid (2011). Tussenmeting Convenant Leerkracht 2011 [Intermediate evaluation Covenant teacher 2011]. Zoetermeer, Netherlands: Research voor Beleid.

Richter, D., Kunter, M., Klusmann, U., Lüdtke, O., \& Baumert, J. (2011). Professional development across the teaching career: Teachers' uptake of formal and informal learning opportunities. Teaching and Teacher Education, 27(1), 116-126. https://doi.org/10.1016/j.tate.2010.07.008

Ryan, R. M., \& Deci, E. L. (2000). Self-determination theory and the facilitation of intrinsic motivation, social development, and well-being. The American Psychologist, 55, 68-78. https://doi.org/10.1037/0003-066X.55.1.68

Ryan, R. M., \& Deci, E. L. (2020). Intrinsic and extrinsic motivation from a self-determination theory perspective: Definitions, theory, practices, and future directions. Contemporary Educational Psychology, 61:101860. https://doi.org/10.1016/j.cedpsych.2020.101860

Schibeci, R. A., \& Hickey, R. L. (2004). Dimensions of autonomy: Primary teachers' decisions about involvement in science professional development. Science Education, 88(1), 119-145. https://doi.org/10.1002/sce.10091|

Schmidt, R. A., \& Bjork, R. A. (1992). New conceptualizations of practice: Common principles in three paradigms suggest new concepts for training. Psychological science, 3(4), 207-217. https://doi.org/10.1111/j.1467-9280.1992.tb00029.x

Scribner, J. P., Sawyer, R. K., Watson, S. T., \& Myers, V. L. (2007). Teacher teams and distributed leadership: A study of group discourse and collaboration. Educational Administration Quarterly, 43(1), 67-100. https://doi.org/10.1177/0013161X06293631

Schunk, D. H., \& DiBenedetto, M. K. (2020). Motivation and social cognitive theory. Contemporary Educational Psychology, 60. https://doi.org/10.1016/j.cedpsych.2019.101832

SEOR (2012). Inventarisatie van lacunes in het opleidings- en scholingsaanbod: Eindrapport [Inventory of shortcomings in education and training opportunities: Final report]. Rotterdam, Netherlands: SEOR.

Shulman, L. (2004). The Wisdom of Practice. San Francisco, CA: Jossey Bass.

Skaalvik, E. M., \& Skaalvik, S. (2014). Teacher Self-Efficacy and Perceived Autonomy: Relations with Teacher Engagement, Job Satisfaction, and Emotional Exhaustion. Psychological Reports, 114(1), 68-77. https://doi.org/10.2466/14.02.PR0.114k14w0

Smylie, M. A. (1992). Teacher participation in school decision-making - Assessing willingness to participate. Educational Evaluation and Policy Analysis, 14(1), 53-67. https://doi.org/10.3102/01623737014001053

Stamos (2013). Werkgelegenheid, in personen, in het basisonderwijs [Employment in primary education]. Retrieved from http://www.stamos.nl/index.rfx?verb=showitem\&item=3.2

Starkey, L., Yates, A., Meyer, L. H., Hall, C., Taylor, M., Stevens, S., \& Toia, R. (2009). Professional development design: Embedding educational reform in New Zealand. Teaching and Teacher Education, 25, 181-189. https://doi.org/10.1016/j.tate.2008.08.007

Stevenson, H., Carter, B., \& Passy, R. (2007) 'New professionalism', workforce remodelling and the restructuring of teachers' work. International Journal of Leadership for Learning, 11(15). Retrieved from https://journals.library.ualberta.ca/iej11/index.php/iejll/article/download/670/331/669

Strauss, A., \& Corbin, J. (1998). Basics of qualitative research: Techniques and procedures for developing grounded theory. Thousand Oaks: Sage

Swann, M., McIntyre, D., Pell, T., Hargreaves, L., \& Cunningham, M. (2010). Teachers' conceptions of teacher professionalism in England in 2003 and 2006. British Educational Research Journal, 36, 549 -571. https://doi.org/10.1080/01411920903018083|

Thoonen, E. E. J., Sleegers, P. J. C., Oort, F. J., Peetsma, T. T. D., \& Geijsel, F. P. (2011). How to improve teaching practices: The role of teacher motivation, organizational factors, and 
leadership practices. Educational Administration Quarterly, 47(3), 496-536. https://doi.org/10.1177/0013161X11400185

Van Eekelen, I. M., Vermunt, J. D., \& Boshuizen, H. P. A. (2006). Exploring teachers' will to learn. Teaching and Teacher Education, 22(4), 408-423. https://doi.org/10.1016/j.tate.2005.12.001

Van Duzor, A. G. (2011). Capitalizing on teacher expertise: Motivations for contemplating transfer from professional development to the classroom. Journal of Science Education and Technology, 20(4), 363-374. https://doi.org/10.1007/s10956-010-9258-z

Vermunt, J. D., \& Endedijk, M. D. (2011). Patterns in teacher learning in different phases of the professional career. Learning and Individual Differences, 21, 294-302. doi.org/10.1016/j.lindif.2010.11.019

Vescio, V., Ross, D., \& Adams, A. (2008). A review of research on the impact of professional learning communities on teaching practice and student learning. Teaching and Teacher Education, 24(1), 80-91. https://doi.org/10.1016/j.tate.2007.01.004

Wallace, C. S., \& Priestley, M. (2011). Teacher beliefs and the mediation of curriculum innovation in Scotland: A socio-cultural perspective on professional development and change. Journal of Curriculum Studies, 43(3), 357-381. https://doi.org/10.1080/00220272.2011.563447

Webb, R., Vulliamy, G., Hämäläinen, S., Sarja, A., Kimonen, E., \& Nevalainen, R. (2004). A comparative analysis of primary teacher professionalism in England and Finland. Comparative Education, 40(1), 83-107. https://doi.org/10.1080/0305006042000184890

Wigfield, A., \& Eccles, J. S. (2000). Expectancy-value theory of achievement motivation. Contemporary Educational Psychology, 25, 68-81. https://doi.org/10.1006/ceps.1999.1015

Wilson, S. M., \& Berne, J. (1999). Teacher learning and the acquisition of professional knowledge: An examination of research on contemporary professional development. Review of Research in Education, 24, 173-209. https://doi.org/10.3102/0091732X024001173 


\section{Appendix}

\section{Tables}

\section{Table 1}

Number of codes (n) and number (nr) and proportion (pr) of teachers with codes, and proportion of teachers with co-occurrences of codes in the group of younger teachers with whom the board decision context was discussed $(N=34)$

$\begin{array}{llllllllllll} & \mathrm{n} & \mathrm{nr} & \mathrm{pr} & \text { aut } & \text { nav } & \text { ncvl } & \text { ncvp } & \text { ncvs } & \text { pav } & \text { pcvl } & \text { pcvp } \\ \text { aut } & 21 & 16 & 0.47 & & & & & & & & \\ \text { nav } & 25 & 13 & 0.38 & 0.06 & & & & & & & \\ \text { ncvll } & 7 & 5 & 0.15 & 0.00 & 0.03 & & & & & & \\ \text { ncvp } & 46 & 22 & 0.65 & 0.06 & 0.21 & 0.03 & & & & & \\ \text { ncvs } & 24 & 15 & 0.44 & 0.03 & 0.12 & 0.12 & 0.06 & & & & \\ \text { pav } & 35 & 20 & 0.59 & 0.12 & 0.06 & 0.00 & 0.06 & 0.00 & & & \\ \text { pcvl } & 32 & 20 & 0.59 & 0.03 & 0.03 & 0.00 & 0.06 & 0.00 & 0.12 & & \\ \text { pcvp } & 46 & 24 & 0.71 & 0.09 & 0.03 & 0.00 & 0.06 & 0.03 & 0.18 & 0.32 & \\ \text { pcvs } & 37 & 19 & 0.56 & 0.06 & 0.00 & 0.00 & 0.03 & 0.12 & 0.09 & 0.24 & 0.15\end{array}$

Table 2

Number of codes ( $n$ ) and number (nr) and proportion (pr) of teachers with codes, and proportion of teachers with co-occurrences of codes in the group of older teachers with whom the board decision context was discussed $(N=26)$

$\begin{array}{llllllllllll} & \mathrm{n} & \mathrm{nr} & \text { pr } & \text { aut } & \text { nav } & \text { ncvl } & \text { ncvp } & \text { ncvs } & \text { pav } & \text { pcvl } & \text { pcvp } \\ \text { aut } & 13 & 13 & 0.50 & & & & & & & & \\ \text { nav } & 21 & 13 & 0.50 & 0.04 & & & & & & & \\ \text { ncvll } & 4 & 2 & 0.08 & 0.00 & 0.00 & & & & & & \\ \text { ncvp } & 36 & 23 & 0.88 & 0.04 & 0.35 & 0.04 & & & & & \\ \text { ncvs } & 10 & 9 & 0.35 & 0.00 & 0.00 & 0.00 & 0.08 & & & & \\ \text { pav } & 30 & 16 & 0.62 & 0.08 & 0.04 & 0.00 & 0.15 & 0.00 & & & \\ \text { pcvll } & 19 & 13 & 0.50 & 0.04 & 0.00 & 0.00 & 0.04 & 0.00 & 0.08 & & \\ \text { pcvp } & 41 & 19 & 0.73 & 0.12 & 0.12 & 0.00 & 0.15 & 0.00 & 0.27 & 0.31 & \\ \text { pcvs } & 25 & 16 & 0.62 & 0.00 & 0.00 & 0.00 & 0.04 & 0.04 & 0.08 & 0.15 & 0.23\end{array}$


Table 3

Number of codes (n), number ( $n r)$ and proportion (pr) of teachers with codes, and proportion of teachers with co-occurrences of codes in the group of younger teachers with whom the team decision context was discussed $(N=25)$

$\begin{array}{llllllllllll} & \mathrm{n} & \mathrm{nr} & \mathrm{pr} & \text { aut } & \text { nav } & \text { ncvl } & \text { ncvp } & \text { ncvs } & \text { pav } & \text { pcvl } & \text { pcvp } \\ \text { aut } & 18 & 13 & 0.52 & & & & & & & & \\ \text { nav } & 8 & 7 & 0.28 & 0.08 & & & & & & & \\ \text { ncvll } & 4 & 4 & 0.16 & 0.00 & 0.00 & & & & & & \\ \text { ncvp } & 17 & 12 & 0.48 & 0.00 & 0.12 & 0.08 & & & & & \\ \text { ncvs } & 10 & 7 & 0.28 & 0.04 & 0.00 & 0.04 & 0.08 & & & & \\ \text { pav } & 41 & 19 & 0.76 & 0.04 & 0.08 & 0.00 & 0.00 & 0.00 & & & \\ \text { pcvll } & 38 & 23 & 0.92 & 0.04 & 0.04 & 0.04 & 0.00 & 0.00 & 0.20 & & \\ \text { pcvp } & 55 & 22 & 0.88 & 0.12 & 0.04 & 0.00 & 0.00 & 0.00 & 0.32 & 0.52 & \\ \text { pcvs } & 45 & 23 & 0.92 & 0.08 & 0.00 & 0.00 & 0.00 & 0.04 & 0.32 & 0.40 & 0.60\end{array}$

Table 4

Number of codes (n), number ( $n r$ ) and proportion ( $p r$ ) of teachers with codes, and proportion of teachers with co-occurrences of codes in the group of older teachers with whom the team decision context was discussed $(N=34)$

$\begin{array}{llllllllllll} & \mathrm{n} & \mathrm{nr} & \mathrm{pr} & \text { aut } & \text { nav } & \text { ncvl } & \text { ncvp } & \text { ncvs } & \text { pav } & \text { pcvl } & \text { pcvp } \\ \text { aut } & 18 & 18 & 0.53 & & & & & & & & \\ \text { nav } & 10 & 9 & 0.26 & 0.03 & & & & & & & \\ \text { ncvll } & 8 & 7 & 0.21 & 0.00 & 0.00 & & & & & & \\ \text { ncvp } & 15 & 11 & 0.32 & 0.03 & 0.03 & 0.06 & & & & & \\ \text { ncvs } & 17 & 12 & 0.35 & 0.00 & 0.06 & 0.12 & 0.09 & & & & \\ \text { pav } & 43 & 19 & 0.56 & 0.06 & 0.06 & 0.03 & 0.03 & 0.03 & & & \\ \text { pcvll } & 39 & 21 & 0.62 & 0.06 & 0.00 & 0.00 & 0.06 & 0.00 & 0.09 & & \\ \text { pcvp } & 49 & 21 & 0.62 & 0.06 & 0.06 & 0.00 & 0.06 & 0.00 & 0.24 & 0.24 & \\ \text { pcvs } & 44 & 27 & 0.79 & 0.03 & 0.03 & 0.03 & 0.00 & 0.06 & 0.15 & 0.27 & 0.18\end{array}$


Table 5

Number of codes (n), number (nr) and proportion (pr) of teachers with codes, and proportion of teachers with co-occurrences of codes in the group of younger teachers with whom the individual decision context was discussed $(N=28)$

$\begin{array}{llllllllllll} & \mathrm{n} & \mathrm{nr} & \mathrm{pr} & \text { aut } & \text { nav } & \text { ncvl } & \text { ncvp } & \text { ncvs } & \text { pav } & \text { pcvl } & \text { pcvp } \\ \text { aut } & 24 & 20 & 0.71 & & & & & & & & \\ \text { nav } & 2 & 2 & 0.07 & 0.04 & & & & & & & \\ \text { ncvll } & 2 & 1 & 0.04 & 0.04 & 0.04 & & & & & & \\ \text { ncvp } & 32 & 22 & 0.79 & 0.07 & 0.07 & 0.04 & & & & & \\ \text { ncvs } & 8 & 6 & 0.21 & 0.00 & 0.00 & 0.00 & 0.04 & & & & \\ \text { pav } & 60 & 27 & 0.96 & 0.14 & 0.04 & 0.00 & 0.04 & 0.04 & & & \\ \text { pcvll } & 44 & 21 & 0.75 & 0.07 & 0.00 & 0.00 & 0.04 & 0.04 & 0.29 & & \\ \text { pcvp } & 102 & 28 & 1.00 & 0.36 & 0.00 & 0.00 & 0.07 & 0.07 & 0.57 & 0.54 & \\ \text { pcvs } & 46 & 22 & 0.79 & 0.00 & 0.00 & 0.00 & 0.04 & 0.00 & 0.25 & 0.39 & 0.50\end{array}$

Table 6

Number of codes (n), number ( $n r$ ) and proportion ( $p r$ ) of teachers with codes, and proportion of teachers with co-occurrences of codes in the group of older teachers with whom the individual decision context was discussed $(N=33)$

$\begin{array}{llllllllllll} & \mathrm{n} & \mathrm{nr} & \mathrm{pr} & \text { aut } & \text { nav } & \text { ncvl } & \text { ncvp } & \text { ncvs } & \text { pav } & \text { pcvl } & \text { pcvp } \\ \text { aut } & 18 & 17 & 0.52 & & & & & & & & \\ \text { nav } & 9 & 7 & 0.21 & 0.03 & & & & & & & \\ \text { ncvll } & 4 & 3 & 0.09 & 0.00 & 0.00 & & & & & & \\ \text { ncvp } & 25 & 15 & 0.45 & 0.00 & 0.03 & 0.06 & & & & & \\ \text { ncvs } & 9 & 6 & 0.18 & 0.00 & 0.00 & 0.03 & 0.03 & & & & \\ \text { pav } & 76 & 31 & 0.94 & 0.09 & 0.06 & 0.00 & 0.12 & 0.06 & & & \\ \text { pcvll } & 41 & 23 & 0.70 & 0.03 & 0.00 & 0.00 & 0.03 & 0.00 & 0.15 & & \\ \text { pcvp } & 96 & 33 & 1.00 & 0.18 & 0.03 & 0.03 & 0.18 & 0.03 & 0.61 & 0.49 & \\ \text { pcvs } & 33 & 22 & 0.67 & 0.06 & 0.00 & 0.00 & 0.03 & 0.00 & 0.24 & 0.24 & 0.49\end{array}$




\section{Citations referred to in the article by respondent number only}

\section{$\S 3.2 .1 .1$.}

o35:19 "I thought those social media laws, that's not my thing. Then I think, but I can do nothing about it, it is a mandatory course, so you can say I don't want to work with it, but you have to."

o58:3 "It just feels very nice to know how to act, to know that you know, and you can do it and then see the effect. It is just a good feeling, for yourself and the child."

y66:8 Regarding a course in cooperative learning "It is very visible throughout the school. It works the same for everyone. So if I teach a different class and I raise my hand they just know what I mean."

y82:10 "It is interesting to work together with colleagues on something, and to know that you're not alone (...) It inspires you to keep talking to each other and find out things together."

\section{$\S 3.2 .1 .2$.}

o92:11 On the consequences of participating in a course "Nieuwsbegrip' (Understanding news) "More enthusiasm about reading comprehension, that's what it has brought about, that children are much more motivated to engage in it."

y48:7 Following a negatively valued course: "No, of course, children are not so aware of what happened behind the scenes. I think for instance that remedial teaching was of inferior quality (...) but the children wouldn't notice."

y60:1 "The inspectorate says 'you should do it like this' or 'you should look at it this way', but then everybody supports it as a team. It was hard work, mainly because the Inspectorate put pressure on it. We were put on orange, and of course you want to get a green ball as a school."

\section{$\S 3.2 .1 .3$.}

y9:12 "Each two weeks a certain didactic format is central, you should really practice with it and sometimes that's a ... then I am already completely tied to my lesson plan. (...) You have to manage so many things, that cooperative didactics loses out."

o70:11 'That course (...) was just a flood of theory and in that case, you go home feeling dissatisfied, because you can do nothing with it."

y23:12 "Of school board members make up lots of things behind their desks. And then it is difficult to keep an open eye for practice. So I always kindly invite board members to walk in our shoes for a week and then come up with the same plan."

o29:6 "Every year something else comes up. (...) And that's a shame. You think, okay, we're in the process of implementing this, and then something new is discovered and we're spending a whole dayseminar on that again."

o11:4 "You can have a lot of people in that room. And they give a lecture, but I prefer reading the material myself. So I think that's a waste of time."

y79:6 "The learning process was its strongest point, I think. They always provide a general curriculum that you can personalize. What is important for me differs from what's important for others around me."

o18:11 "I would have preferred that the course had stated its goals clearly from the outset. This and this is what you are expected to have mastered at the end of the course."

y17:4 Following a course on stimulating literacy and about ways of preparing students for short literacy tests "I like to experiment, does this work, can I do it and is it fun." 
y64:2 "And what is important too, it was taught in an attractive, exciting way by the course leader."

035:16 "My expectations for the day were not too high. (...) The legal framework for social media, I thought, 'geez, we're in for a long story'. She [the PD instructor] hadn't much choice, did she? Since you have to tell it and I don't think that's inspiring."

o43:10 "It wasn't a real education course, it was workshops äll the way (...) You hear the theory for once, you see some examples, you may practice for half an hour in a training centre. And then you go back to your school and do it all by yourself, in between teaching and parent-teacher conferences."

\section{$\S 3.2 .1 .4$.}

y9:16 "That you are working with it and you really see that it does something for the child and for yourself as well, when you see real progress."

y60:7 "The course was very intense. But then, when you see the standardised test scores printout and you think, 'geez, have they improved', then I think that's positive. I haven't spent my time in vain."

y65:4 On the consequences of participating in this PD activity "Looking critically at our children here at school. Looking critically at yourself. Are you...ehm are you observing adequately... ehm where are your weaknesses? Are you prejudiced?"

\section{$\S 3.2 .2$.}

y52:5 "I was steering my learning process myself in this activity, yes, but that was because I organized it myself."

y48:4 "Yes, I had some influence on the course. Of course, there was a fixed format: this is the way to make a plan, but $\mathrm{H}$. [course leader] is always very ... we make it really fit the school, so I have left out some things and added others and he was okay with all of that."

o50:5 'If I told them, 'look here, this is way too fast for me' they said to me 'come sit next to me' and 'this way you can develop a group plan (...)' and 'we have implemented it like this, have you thought about that?' I got very good guidance.”

y17:11-21 On her mandatory master in Special Educational Needs "you had to desal with tests, six tests during the course and in the end you were obliged to pass the exam, that was it, there was some pressure involved, you had to do this and you had to do that, and that's not my cup of tea (...) And we had to make a test about change processes and you were allowed to choose a case. I thought it would be nice to choose a case that I like and that meets the goals of the test and that would help my team. And this how I came to work on collaborative learning and wrote a complete handbook for each teacher."

\section{$\S 3.2 .3$.}

O18:8 "Of course, it always brings you something, it's what you get out of it yourself. And you always hear new things, that make you think (...). However, whether you really have to sit out a whole afternoon with all the work waiting for you...?"

y36:16 "A whole day, for me a waste of time, (...) but for the students as well, because it could have been a day more to learn something for them."

Y9:15) "It looks as if I have an administrative job next to my teaching which is in itself a lot of work (...) and you have to pay attention always, because it doesn't belong to... it's something extra." 


\section{Coding categories Cognitive Valences}

\subsection{School context}

Definition: the school as a decision and work context with its task loads, work routines and schedules, colleagues, and leadership impacting teacher PD valuations.

Text examples: see $\S 3.2 .1 .1$. paper and Appendix 2.

Transfer

Definition: Transfer of (positive or negative) valuations of the locus of decision-making regarding PD participation unto the valuation of ensuing PD experiences per se.

Fit with workload and work schedule

Definition: levels of fit of PD with workload and work schedules (positively or negatively) impacting PD valuations.

Support of the principal for PD participation

Definition: (lack of) support by school principals in their participation in PD impacting teacher PD valuations.

\subsection{Stakeholder consequences of PD}

Definition: positive and/or negative consequences of PD participation for stakeholders such as the students, the teachers personally and the school impacting teacher PD valuations.

Text examples: see $\S 3$ 3.1.2. paper and Appendix 2.

\section{Students}

Definition: both students in the classroom of the teacher as those in their school.

Teachers

Definition: text fragments must pertain to or include the interviewed teacher personally.

School

Definition: consequences for the school as an organization, for all the schoolteachers, for the school curriculum, school policies, and for (the relations with) the parents of the students.

\subsection{Qualities of PD content and design}

Definition: content and design and delivery of PD as such or in relation to learning needs and preferences of teachers and their classrooms impacting teacher PD valuations.

Text examples: see $\S 3.2 .1 .3$. paper and Appendix 2.

Immediate applicability of PD

Definition: PD content and/or what teachers learn from PD permits or impedes speedy application in their classroom.

Novelty of PD content

Definition: (Lack of) earlier experience with PD content impacting teachers PD valuations.

PD learning arrangements

Definition: text fragments referring to ways of distributing, reflecting on and working with PD information and knowledge and connecting it to learning needs and preferences of teachers and to classroom and school realities. 


\section{Coding Categories Autonomy}

Definition: text fragments in which teachers refer to their steering of important aspects of PD or their making use of perceived freedom of action related to PD. Instances of steering can occur in preparation of, during and in selecting what is (not) taken from PD to the school.

Text examples: see $\S 3.2$. 2. paper and Appendix 2.

Positive autonomy

Definition: the experience of steering one's own learning process in PD or of being offered a level of freedom of action within PD is valued positively by the teacher.

Negative autonomy

Definition: the experience of steering one's own learning process in PD or of being offered a level of freedom of action within PD is valued negatively by the teacher.

Absence of autonomy

Definition: the feeling of steering one's own learning process or the experience of freedom of action with regard to PD was absent and this absence was not linked to positive nor negative valuations. 